\title{
Biofabrication strategies for 3D in vitro models and regenerative medicine
}

Citation for published version (APA):

Moroni, L., Burdick, J. A., Highley, C., Lee, S. J., Morimoto, Y., Takeuchi, S., \& Yoo, J. J. (2018).

Biofabrication strategies for $3 \mathrm{D}$ in vitro models and regenerative medicine. Nature reviews materials, 3(5), 21-37. https://doi.org/10.1038/s41578-018-0006-y

Document status and date:

Published: 01/05/2018

DOI:

10.1038/s41578-018-0006-y

Document Version:

Publisher's PDF, also known as Version of record

Document license:

Taverne

Please check the document version of this publication:

- A submitted manuscript is the version of the article upon submission and before peer-review. There can be important differences between the submitted version and the official published version of record.

People interested in the research are advised to contact the author for the final version of the publication, or visit the DOI to the publisher's website.

- The final author version and the galley proof are versions of the publication after peer review.

- The final published version features the final layout of the paper including the volume, issue and page numbers.

Link to publication

\footnotetext{
General rights rights.

- You may freely distribute the URL identifying the publication in the public portal. please follow below link for the End User Agreement:

www.umlib.nl/taverne-license

Take down policy

If you believe that this document breaches copyright please contact us at:

repository@maastrichtuniversity.nl

providing details and we will investigate your claim.
}

Copyright and moral rights for the publications made accessible in the public portal are retained by the authors and/or other copyright owners and it is a condition of accessing publications that users recognise and abide by the legal requirements associated with these

- Users may download and print one copy of any publication from the public portal for the purpose of private study or research.

- You may not further distribute the material or use it for any profit-making activity or commercial gain

If the publication is distributed under the terms of Article $25 \mathrm{fa}$ of the Dutch Copyright Act, indicated by the "Taverne" license above, 


\title{
REVIEWS
}

\section{Biofabrication strategies for 3D in vitro models and regenerative medicine}

\author{
Lorenzo Moroni ${ }^{*}$, Jason A. Burdick $\mathbb{1}^{2}$, Christopher Highley², Sang Jin Lee $\mathbb{B}^{3}$, \\ Yuya Morimoto 4 , Shoji Takeuchi ${ }^{4}$ and James J. Yoo ${ }^{3}$
}

Abstract | Organs are complex systems composed of different cells, proteins and signalling molecules that are arranged in a highly ordered structure to orchestrate a myriad of functions in our body. Biofabrication strategies can be applied to engineer 3D tissue models in vitro by mimicking the structure and function of native tissue through the precise deposition and assembly of materials and cells. This approach allows the spatiotemporal control over cell-cell and cell-extracellular matrix communication and thus the recreation of tissue-like structures. In this Review, we examine biofabrication strategies for the construction of functional tissue replacements and organ models, focusing on the development of biomaterials, such as supramolecular and photosensitive materials, that can be processed using biofabrication techniques. We highlight bioprinted and bioassembled tissue models and survey biofabrication techniques for their potential to recreate complex tissue properties, such as shape, vasculature and specific functionalities. Finally, we discuss challenges, such as scalability and the foreign body response, and opportunities in the field and provide an outlook to the future of biofabrication in regenerative medicine.

${ }^{1}$ MERLN Institute for Technology-Inspired Regenerative Medicine, Department of Complex Tissue Regeneration, Maastricht University, Maastricht, Netherlands.

${ }^{2}$ Department of

Bioengineering, University of Pennsylvania, Philadelphia, $P A$, USA.

Institute of Industrial Science, University of Tokyo, Tokyo, Japan.

${ }^{4}$ Wake Forest Institute for Regenerative Medicine, Wake Forest School of Medicine, Winston-Salem, NC, USA

*e-mail:..moroni@ maastrichtuniversity.nt https://doi.org/10.1038/ s41578-018-0006-y
Tissue engineering and regenerative medicine aim to develop replacement tissues for our body ${ }^{1}$. Various cell types, biomaterials and stimulatory signals (for example, growth factors and mechanical signalling), either alone or in combination, have been explored for their potential to support tissue repair and regeneration and to recreate the structure and/or function of tissues. Progress in cell and material technologies, such as automation of cell culture, techniques for cell selection and new material formulations for photolithography and bioprinting, has led to the development of more efficient therapies for the repair of simple tissues in the laboratory and in preclinical models. However, self-sustaining solutions that facilitate full tissue integration and homeostasis in a timely manner remain elusive $e^{2,3}$.

Biofabrication technologies enable the fabrication of biological constructs with precise control over the positioning of cells and biomaterials (BOX 1). Bioprinting and bioassembly constitute the two major biofabrication pillars, and various techniques have been developed (FICS. 1, 2). Bioprinting allows the spatial arrangement of cells, materials and biologically active factors, whereas bioassembly facilitates the automated assembly of cellcontaining building blocks ${ }^{4}$. These techniques provide a high level of biomimicry by recreating the complexity of tissues and organs, and they can be upscaled for manufacturing and production. Importantly, biofabrication strategies allow the spatiotemporal modulation of cell-cell and cell-extracellular matrix (ECM) interactions $s^{5,6}$ through the formulation and use of engineered materials, such as hydrogels, that enable cells to migrate and that can be remodelled for ECM deposition. In bioprinting, the synthetic or natural materials used to recreate tissues are processed together with cells and/or biomolecules and are often termed bioinks.

High spatial and temporal resolution is important for the fabrication of complex tissues for therapies and for the creation of $3 \mathrm{D}$ in vitro models to investigate biological processes $^{7-9}$. Traditional approaches to fabricating engineered scaffolds, such as porogen leaching or gas foaming, do not allow for the simultaneous incorporation of biologically relevant signals and cells with high spatial control. Biofabrication technologies can be used to pattern cells and materials at such high resolution; however, whole organ regeneration is not yet possible. Better control over the biological processes guiding tissue regeneration needs to be achieved, and materials and technologies need to be developed that can adequately and dynamically replicate these processes at (sub)cellular resolution.

In this Review, we discuss biofabrication technologies in the context of tissue and organ models and implantable constructs. We highlight advances in biomaterials 


\section{Box 1 | Biofabrication}

\section{Biofabrication}

In regenerative medicine, biofabrication is the automated generation of structurally organized, biologically functional products from living cells, bioactive molecules, biomaterials, cell aggregates such as microtissues or hybrid cell-material constructs through bioprinting or bioassembly, and subsequent tissue maturation processes ${ }^{4,15}$

\section{Bioprinting}

Bioprinting is the use of computer-aided transfer processes for the patterning and assembly of living and non-living materials with a defined 2D or 3D architecture to produce bioengineered structures for regenerative medicine, pharmacokinetic and basic cell biology studies. This includes the additive manufacturing of scaffolds designed to control cell activity for tissue repair or regeneration (for example, through hierarchical structure or surface engineering).

\section{Bioassembly}

Bioassembly is the fabrication of hierarchical constructs with a defined 2D or 3D organization through automated assembly of preformed cell-containing fabrication units generated through cell-driven self-organization or assembly of hybrid cellmaterial building blocks, which is typically done by applying microfabricated moulds or microfluidics ${ }^{4,15}$.

\section{Biomaterials}

Biomaterials are used as (part of) a medical device or an advanced medical product to replace, restore or regenerate a tissue or organ and its function ${ }^{15}$. Biomaterials comprise non-toxic synthetic or natural polymers, such as hydrogels (water-swollen polymer networks), extracellular matrices, shape memory materials, ceramics and metals. If biomaterial properties are designed to modulate cell activity in vitro and in vivo, they are referred to as instructive biomaterials.

\section{Bioinks}

Bioinks are biomaterials that are processed by bioprinting and that contain biological molecules and/or cells ${ }^{15}$. have been dominated by materials that rapidly stabilize from a non-viscous state, for example, alginate, which is rapidly crosslinked by calcium ions, and gelatinmethacrylate (GelMA), which crosslinks through cooling or light ${ }^{16-18}$ (FIG. 2b). Because of its innate biofunctionality and tunability, GelMA has been used alone or in combination with silk fibroin for the bioprinting of constructs with optimized biophysical properties ${ }^{19,20}$. Alginate continues to be useful in stabilizing other materials to enable inkjet printing of silk fibroin ${ }^{21,22}$ or to support heterogeneous, multimaterial extrusion techniques. Modifications to printer hardware, such as photopermeable nozzles and switchable print heads fed from multiple reservoirs, will expand the possibilities for materials ${ }^{23}$ and complexity ${ }^{22,24}$ in biofabrication.

\section{Supramolecular materials as bioinks}

Materials crosslinked by physical, non-covalent bonds have increased solution viscosity and thus exhibit shear thinning during flow. For example, hydrogen bonds in $\beta$-sheets of recombinant spider silk proteins ${ }^{25}$ or in guest-host interactions of $\beta$-cyclodextrin or adamantane in modified hyaluronic acid (HA) polymers ${ }^{26}$ are broken under shear stress, enabling bioprinting by extrusion, which is followed by rapid stabilization upon deposition. Covalent crosslinking can then be applied to stabilize the structure. Supramolecular DNA hybridization has also been used in combination with inkjet bioprinting to crosslink polypeptides that are functionalized with single-stranded DNA, resulting in a material that can be degraded by either proteases or nucleases ${ }^{27}$. Alternatively, complementary peptide binding domains can be grafted onto polymers, such as alginate, to maintain a homogeneous cell suspension and to help shield cells from shear stress during the extrusion process. In the case of modified alginate, calcium can provide a stabilizing secondary crosslink upon extru$\operatorname{sion}^{28}$. Finally, bioinks made of short, self-assembling peptides form soft, injectable hydrogels and thus offer possibilities for customized bioprinted constructs owing to their ease of functionalization ${ }^{29}$. functionality can be created using chemistries such as photo-mediated degradation or crosslinking ${ }^{10}$. Highthroughput screening of different material variations ${ }^{11}$ enables the rapid design of specific material formulations, and various biomaterials are in use as cell-instructive and biomimetic environments for regenerative medicine ${ }^{12-14}$.

Materials used in biofabrication must meet specific criteria, depending on the respective technique (for example, extrusion or inkjet bioprinting, photopatterning and lithography or formation and assembly of modular components (FICS. 1, 2, 3)). The spatial resolution of bioprinted structures ranges from the nanometre to the millimetre scale and is dependent on the biofabrication technology ${ }^{15}$. Biomaterials termed bioinks refer to biomaterials that incorporate cells.

\section{Biomaterials for extrusion bioprinting}

Extrusion-based bioprinting is one of the most commonly used biofabrication techniques (FICS. 1, 2a). In this technique, a material must exhibit steady flow until deposition and must rapidly stabilize upon delivery. Historically, material formulations used in bioprinting

\section{Hydrogels as support materials}

Shear-thinning hydrogels and viscoplastic materials can be used as dynamic support materials for bioprinting. For example, the printed material can be directly deposited into a reservoir of support material ${ }^{30}$, or alternatively, poloxamers can be extruded to create a pattern of divergent and convergent channels ${ }^{31}$. Hydrogel inks can also be directly deposited into a gelatin-particle slurry by the use of granular medium that fluidizes upon the movement of the print head. This approach can be applied to support physiological structures with large void spaces, such as heart constructs ${ }^{32}$ (FIG. 4a). Similarly, jammed carbomer microparticles ${ }^{33}$ can support the printing of complex structures, such as hierarchical multiscale branching structures, which cannot be bioprinted without support (FIG. 4b). A self-healing support hydrogel can be designed by introducing supramolecular guest-host modifications, which enable rearrangement of the polymeric network and thus adaption to the bioprinted material ${ }^{34}$. This approach allows the 


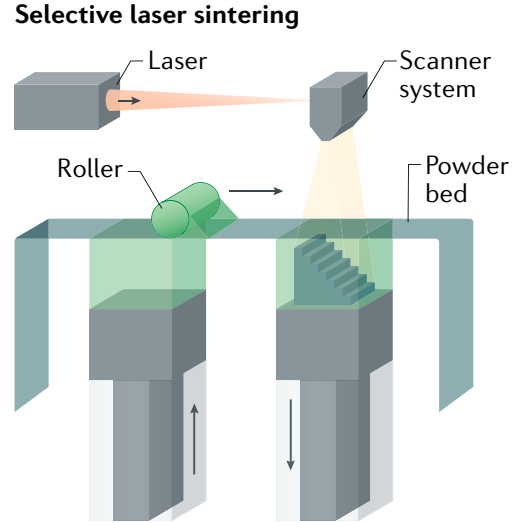

c 3D printing

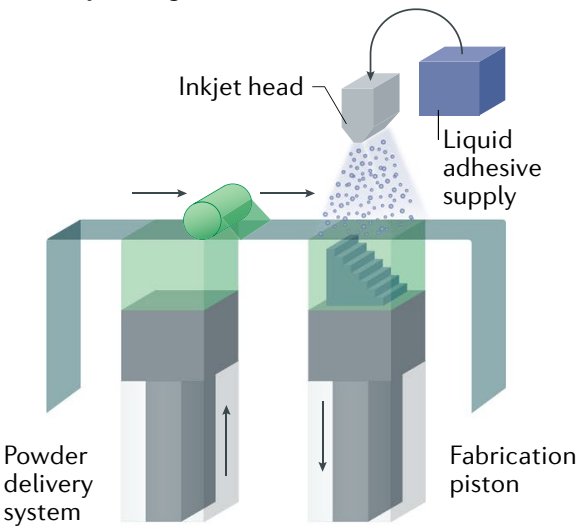

b Stereolithography

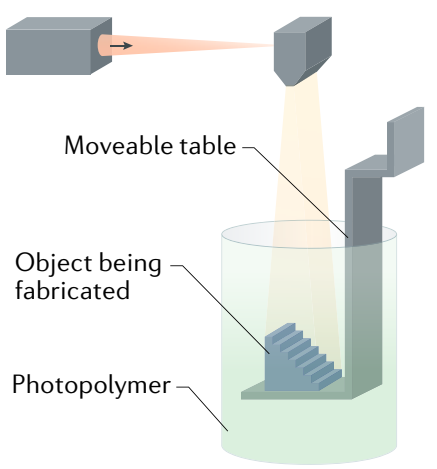

d Fused deposition modelling

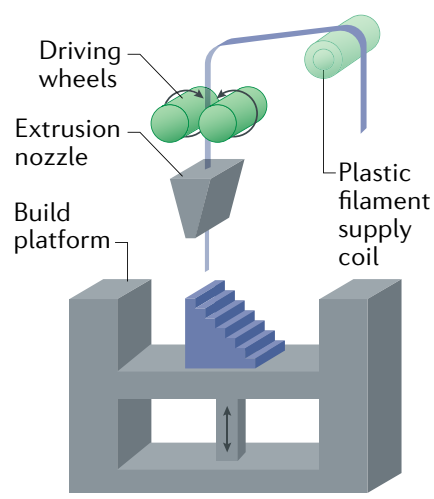

e 3D plotting

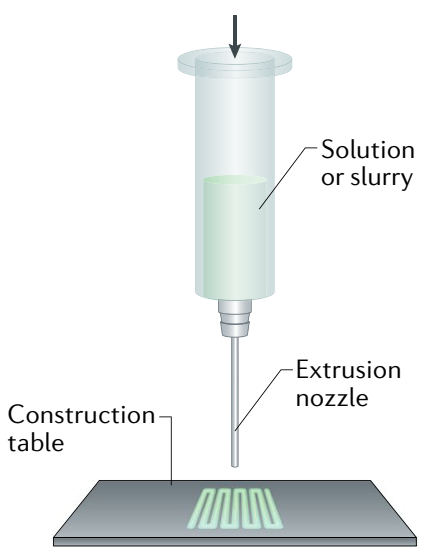

g Solution and melt electrospinning

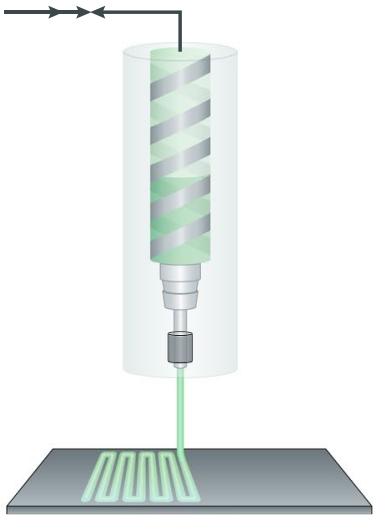

f Two-photon polymerization

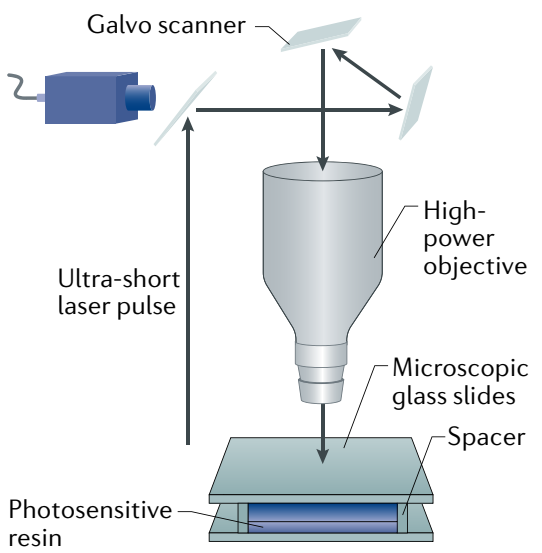

resin

Solution electrospinning

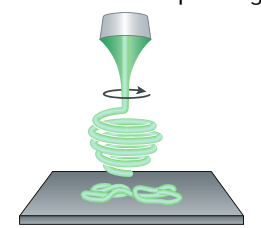

Melt electrospinning

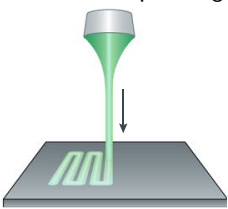

Fig. 1 | Bioprinting and bioassembly techniques.

a | Selective laser sintering creates scaffolds by scanning a powder bed with a laser beam and by locally sintering the hit grains. b| Stereolithography creates scaffolds by selectively exposing a photopolymer with a light source. c $3 \mathrm{D}$ printing is used to fabricate scaffolds by ejecting a binder onto a powder bed of material. d,e $\mid$ Fused deposition modelling and 3D plotting fabricate scaffolds by extruding a material (either in filament or pellet form) through a nozzle by pressure. $\mathbf{f} \mid$ Two-photon polymerization is applied to develop scaffolds through focusing a light source on a specific point within a biomaterial. $\mathbf{g}$ Solution and melt electrospinning are used to produce fibrous structures from polymer melts and solutions by applying electric force. Panels $\mathbf{a}-\mathbf{c}$ and $\mathbf{f}$ are adapted from Peltola, S. M. et al. A review of rapid prototyping techniques for tissue engineering purposes, Annals. of Medicine (2008) REF. ${ }^{238}$, by permission of Taylor $\mathcal{E}$ Francis Ltd. Panels e and $\mathbf{g}$ are adapted with permission from REF. ${ }^{15}$, Elsevier.

disposition of arbitrary, high-resolution structures in 3D (FIG. 4C). A bisphosphonate-modified HA, crosslinked through coordination with calcium ions, can also serve as support material ${ }^{35}$.

The use of support materials enables the direct patterning of structures and functionalities into hydrogel ${ }^{34,35}$, the creation of fine channels $\mathrm{s}^{31-34,36,37}$ and the deposition of hydrogel structures with large internal voids $\mathrm{s}^{32-34}$. Bioprinting into a granular medium allows the fabrication of structures from a range of materials and supports scaffold-free deposition of cells ${ }^{38}$, facilitating the direct deposition of cell aggregates ${ }^{39}$. Therefore, the amount of biomaterial required to deposit cells can be reduced to better reflect the architecture of native tissues ${ }^{40}$. For example, cell-sheet-based bioinks ${ }^{41}$ enable the bioprinting of cell aggregates to compose dense cellular structures ${ }^{42}$.

\section{High-viscosity and low-viscosity materials}

The deposition of highly viscous, thixotropic ${ }^{43}$ and nonviscous materials has been facilitated through adaptions in the curing process during bioprinting ${ }^{23}$. Viscous inks exhibiting kinetics that prevent deposition in the solution phase can be extruded as microparticles, which are cured before deposition. For example, poly(dimethylsiloxane) (PDMS) microspheres have a long cure time. When wetted with a thin layer of uncured liquid precursor, the particles are held together through capillary action, which enables their curing into robust, elastomeric structures ${ }^{43}$. Low degrees of covalent crosslinking of low-viscosity solutions before extrusion also facilitate the precise control of rheological properties of bioinks to ensure printability; for example, gelatin and fibrinogen can be crosslinked with an amine-reactive polyethylene glycol (PEG) crosslinker ${ }^{44}$. The bioprinting process can also be designed to allow photocrosslinking through a transparent nozzle and thus low-viscosity materials can be printed as stable filaments. Light exposure after deposition results in material flow, and light exposure before extrusion leads to material fracture $^{23}$. This technique enables the bioprinting of bioinks from a wide range of materials commonly used in tissue engineering, such as norbornene-modified HA, GelMA and PEG diacrylate (PEGDA) ${ }^{23}$. 

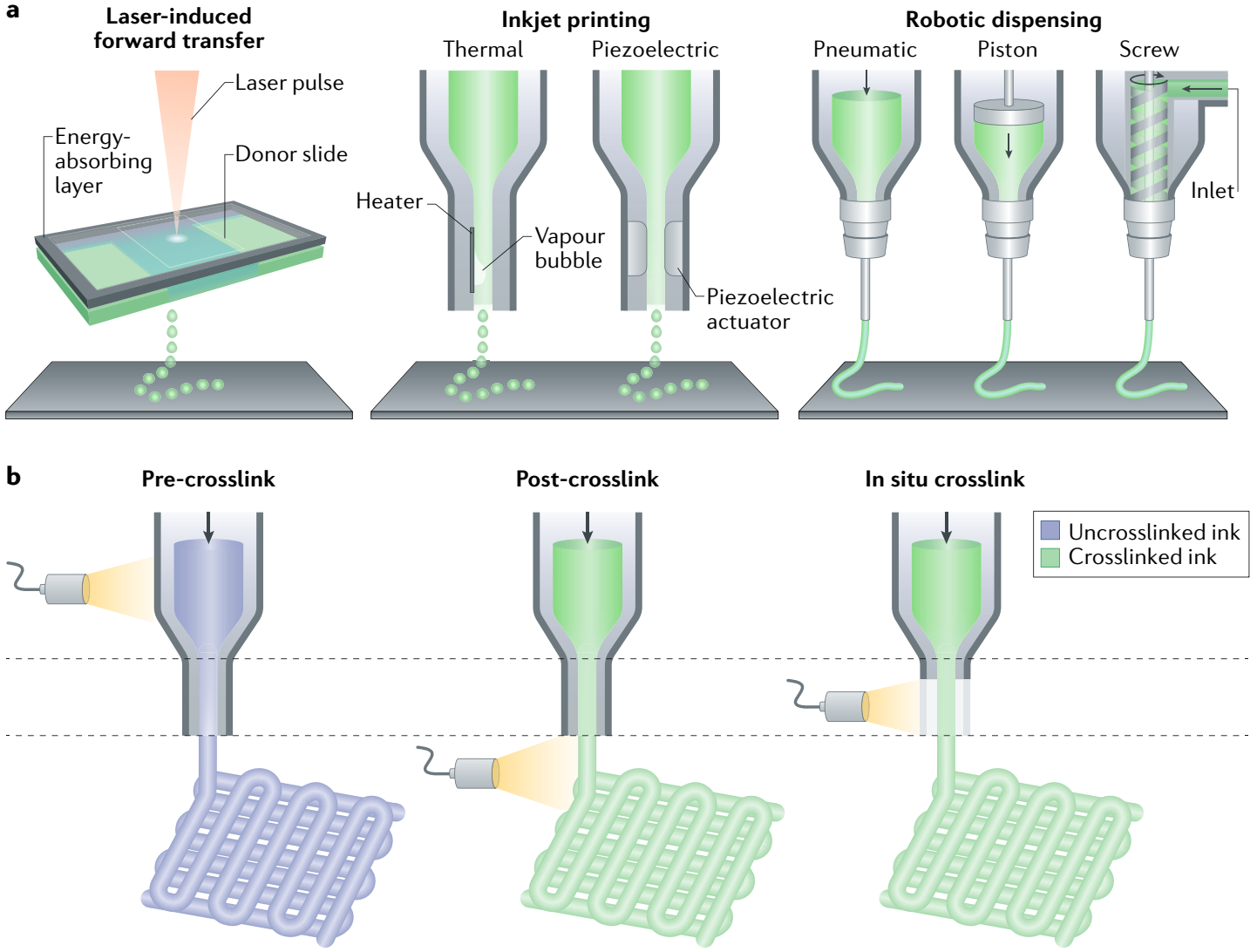

Fig. 2 | Hydrogel bioprinting. a | Cell-laden hydrogel scaffolds are created by applying laser light (laser-induced forward transfer) or by extrusion (inkjet printing with or without robotic dispension). $\mathbf{b}$ | Light-induced crosslinking strategies for the bioprinting of photocrosslinkable bioinks are shown. Crosslinking can be triggered before (pre-crosslink), after (post-crosslink) or during (in situ crosslink) extrusion. Panel $\mathbf{a}$ is adapted with permission from REF. ${ }^{239}$, John Wiley and Sons. Panel $\mathbf{b}$ is adapted with permission from REF. ${ }^{23}$, John Wiley and Sons.

\section{Photocrosslinkable bioinks}

Light-based chemistries allow for the development and spatiotemporal control of materials with dynamic physicochemical properties ${ }^{10,45}$. Bioinks that react in the presence of light are important for standard additive manufacturing technologies and enable the fabrication of 3D structures through photopatterning. Many photochemical reactions are limited by oxygen attenuation of radicals; however, this issue can be addressed using thiolene photoactivated chemistries ${ }^{46}$. Allyl-functionalized and thiol-functionalized linear poly(glycidol) combined with a photoinitiator is rapidly crosslinked upon bioprinting in the presence of UV light ${ }^{47}$, yielding high bioprint fidelity to computer design ${ }^{48}$. For example, allylated gelatin constitutes a highly tuneable bioink that can be used for a variety of printing methods ${ }^{49}$. Similarly, the highly specific thiolnorbornene click chemistry reaction can be exploited to crosslink a norbornene-modified poly(glycerol sebacate) as an elastomeric ink ${ }^{50}$. Thiol-ene crosslinking allows the design of bioprintable hydrogels with dynamic properties, for example, through the incorporation of enzymatically degradable dithiol crosslinks.

Photocrosslinkable bioinks are central to lithographybased biofabrication techniques ${ }^{51}$ (FIG. 2b). The multiscale capabilities of lithography-based bioprinting enable the printing of materials, such as biocompatible PEGDA and PEG dimethacrylate (PEG-DMA) ${ }^{52}$, that polymerize through a radical chain growth mechanism into single multiscale and multimaterial structures. In this process, oxygen inhibition results in the formation of a thin unreacted layer to which additional material is bound. Similarly, digital light processing can be used to fabricate structures on a cellular scale in PEGDA and GelMA with high fabrication speed ${ }^{53}$. Digital light processing can also be used for the patterning of high-resolution vasculature using GelMA scaffolds that contain $\mathrm{HA}^{54}$.

\section{Photodegradable materials}

In addition to photoactive materials used in additive lithographic approaches, materials can also be designed to locally degrade in response to a light cue, which can be exploited for the spatial control of material dynamics. By directing the focus of a nanosecond pulsed laser to specific volumes of a material, fine channels and microfluidic networks can be patterned into hydrogels, which are fabricated from ECM proteins, polysaccharides or synthetic polymeric networks through the physical ablation of covalent bond ${ }^{55}$. For example, high-resolution channel structures can be patterned into PEG hydrogels through photolysis of synthetic peptide crosslinks that contain ortho-nitrobenzyl ester functionalities ${ }^{56}$. Such powerful, high-resolution laser-based patterning methods considerably improve the resolution of biofabrication techniques. 

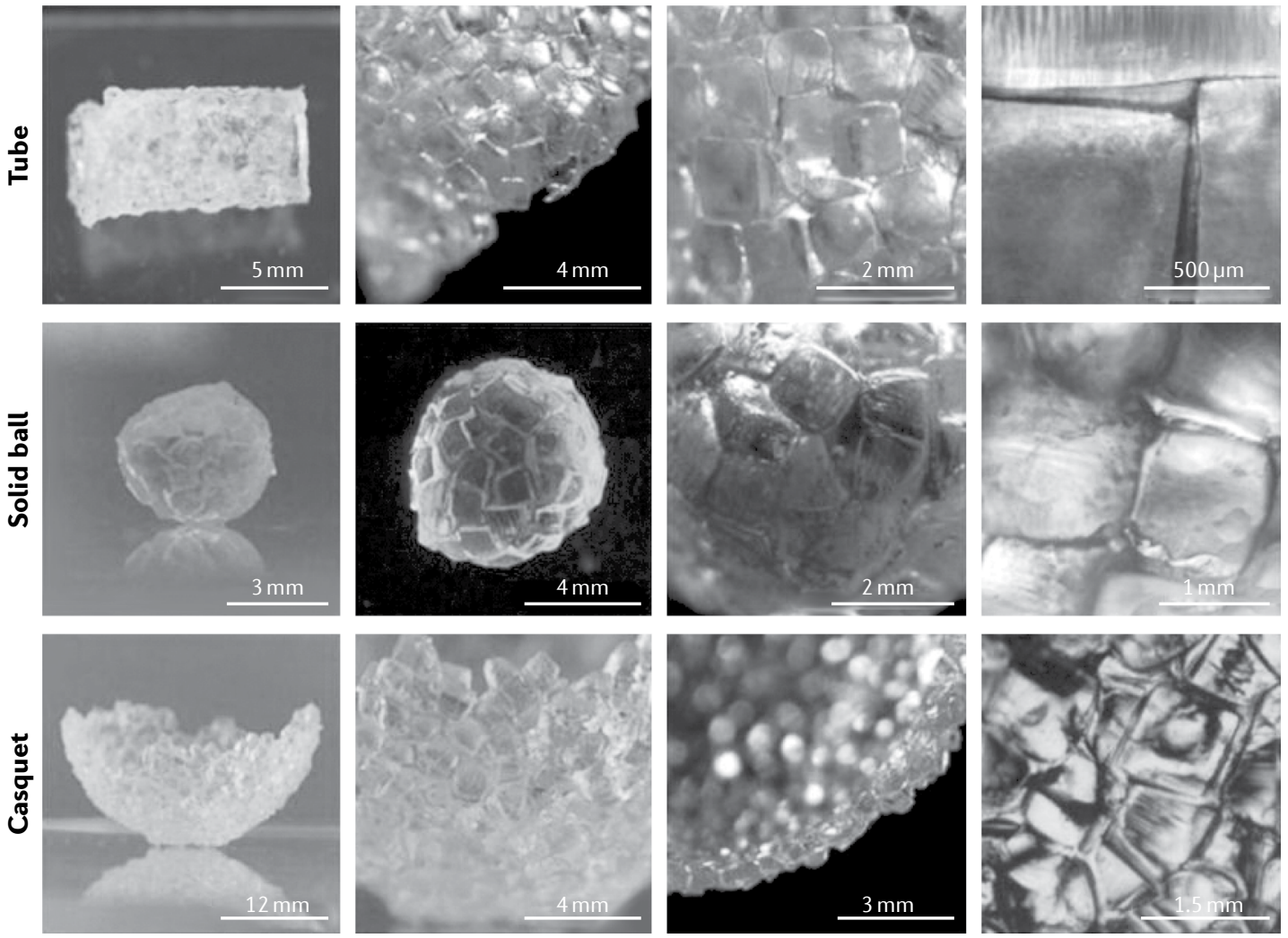

Fig. 3 | Bioassembly of tissue-like constructs. Tubular, spherical and casquet-shaped tissue-like structures can be created by automated assembly of cellular spheroids or cell-laden hydrogel building blocks that fuse together because of tissue liquidity principles (cellular spheroids) or secondary interactions (cell-laden microgels). Reproduced with permission from REF. ${ }^{207}$, John Wiley and Sons.

\section{Natural biomaterials}

An important area of research is the development of bioinks from natural materials ${ }^{57}$, such as collagen ${ }^{58,59}$, decellularized $\mathrm{ECM}^{60-62}$, gelatin ${ }^{23,63-65}$, alginate ${ }^{66,67}$, $\mathrm{HA}^{23,26,34,35}$ and silk ${ }^{21,68,69}$, because of their inherent biocompatibility and the possibility to harvest the biochemical and biophysical cues present in natural cellular microenvironments to control cell behaviour ${ }^{70}$. Decellularized materials from a variety of tissue types can be formulated as bioinks and deposited using poly( $\varepsilon$-caprolactone) (PCL) supports ${ }^{61}$. Biofabrication enables the deposition of natural materials to reproduce the structural and chemical organization of native tissues. However, challenges remain to make natural materials printable and to achieve biologically relevant mechanical properties ${ }^{57}$.

\section{Cells in bioinks}

The term bioink refers to biomaterials that incorporate cells. Bioprinting of materials that contain cells faces several challenges. Stress, such as physical or chemical perturbations that occur during the bioprinting process, may affect cell behaviour and survival. The cell density needs to be sufficiently high to achieve multicellular architectures in the bioprinted material. The incorporation of cells may also alter the properties of the biomaterial, and finally, the material can be toxic for cells.

Cells are typically included in bioinks at concentrations on the order of ten million cells per millilitre; this concentration corresponds to approximately $\leq 5 \%$ of the total bioink volume. At these concentrations, the presence of cells has a negligible effect on the rheological properties of the bioink during extrusion ${ }^{71}$. By contrast, the incorporation of cells affects droplet formation in jetting processes ${ }^{72,73}$. Bioink properties are also expected to change with increasing cell numbers, which is similar to composite material systems, in which high densities of included cells and particles modify mechanical and rheological properties ${ }^{74,75}$. Notably, how the nonlinear viscoelastic behaviour of cells ${ }^{76}$ impacts the properties of bioinks remains elusive.

Bioprinting of cell clusters ${ }^{39,77}$ and shielding of dense cell populations from shear stress through core-shell flows ${ }^{78}$ can be applied to increase the viability of cells in a bioprinted construct. Cell viability can also be improved by decoupling the cells from the bioink, for example, through the use of microspheres as cell carriers ${ }^{79}$ or the encapsulation of cells in protective microgels ${ }^{80}$. Ultimately, both bioink formulations and biofabrication processes need to be tailored to maintain cell viability to yield high densities of viable cells.

\section{In vitro 3D models}

In vitro $3 \mathrm{D}$ tissue models offer the opportunity to investigate the safety and efficacy of biochemical agents, for example, for drug development, and to model biological processes, such as tissue development and disease. Numerous normal and diseased 

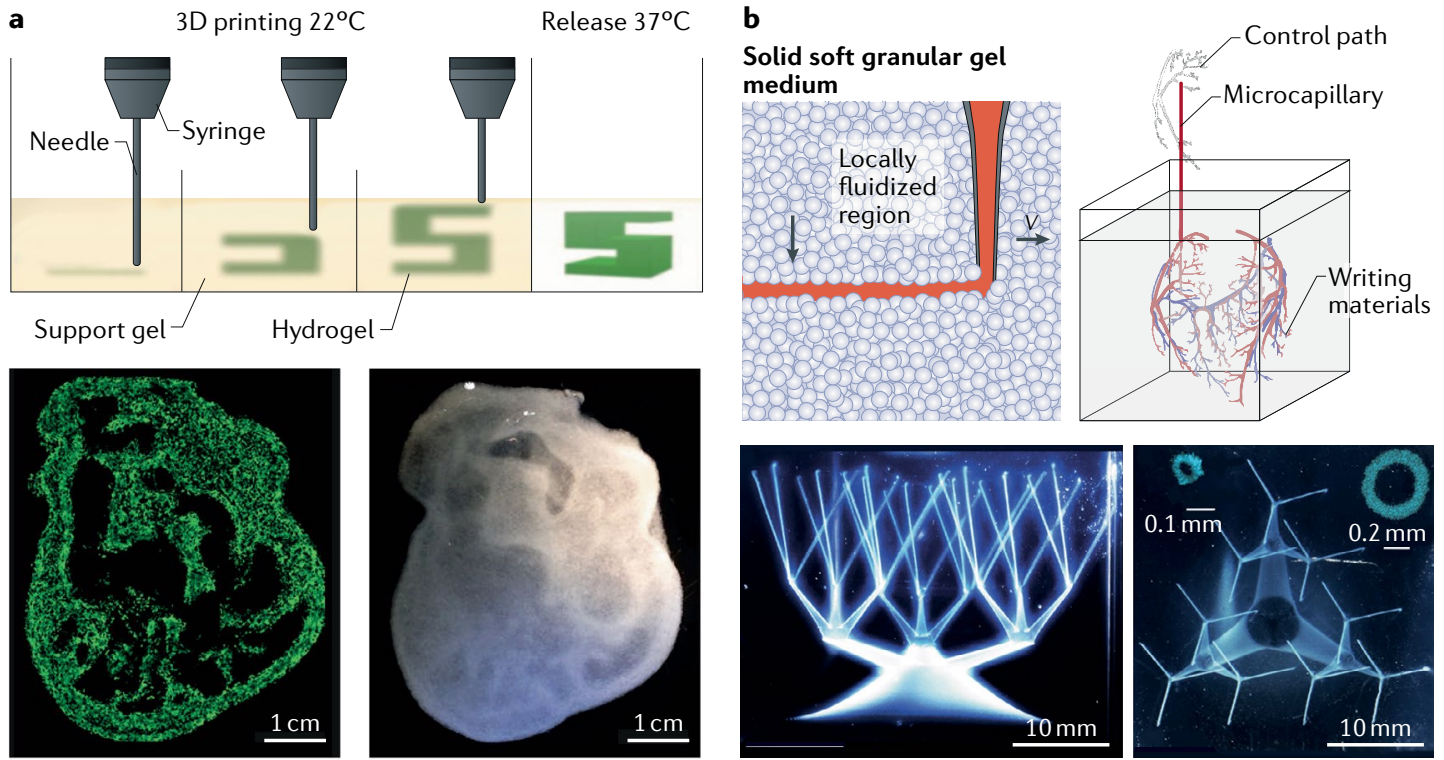

C

Freestanding structures

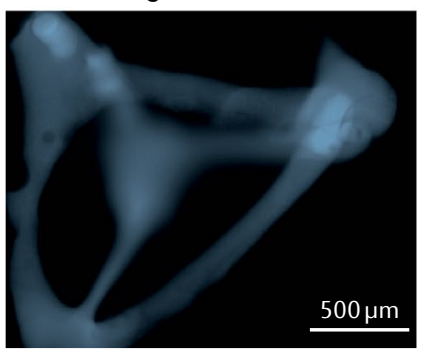

Structures within support gel
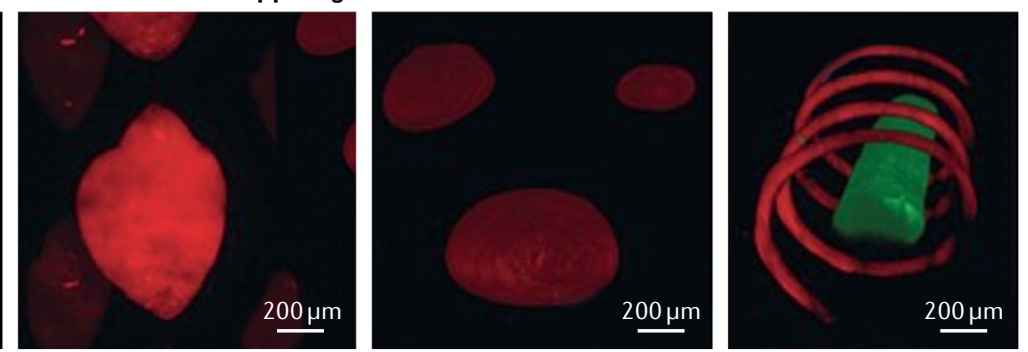

Fig. 4 | Bioprinting in support materials. Self-healing hydrogels can be used as support media for bioprinting to enable the 3D fabrication of structures. a | A gelatin slurry can be used for the fabrication of hydrogel structures with large void spaces, for example, heart constructs. The hydrogel (green) is extruded and crosslinked within the gelatin slurry support (yellow). The $3 \mathrm{D}$ object is then released through melting of gelatin at $37^{\circ} \mathrm{C}$. Using this method, an embryonic chicken heart can be fabricated on the basis of a 3D computer-aided design model. The bioprinted tissue construct made using fluorescent alginate (green) exhibits the same internal trabecular structure as an embryonic chicken heart. $\mathbf{b} \mid \mathrm{A}$ granular medium composed of carbomer microgels enables 3D printing of multiscale hierarchical structures, for example, continuous branched tubular networks of hollow vessels. The network of hollow tubes shown in the microscopy images was printed using polyvinyl alcohol, starting from a $25 \mathrm{~mm}$ diameter circular base and tapering to 27 capillaries with a diameter of $100 \mu \mathrm{m}$ and a wall thickness of $100 \mu \mathrm{m}$. The insets show confocal cross sections. c $\mid$ Hydrogels crosslinked by non-permanent, shear-thinning and self-healing bonds support the printing of high-resolution structures. Support material or printed ink can be removed after processing to produce complex structures that are freestanding or that contain voids and channels. The confocal microscopy images show a freestanding 3D tetrahedron made of photocrosslinked methacrylate-modified hyaluronic acid (blue), a rhodamine-labelled spherical structure (red) in an unlabelled support hydrogel and a fluorescein-labelled filament (green) with a rhodamine-labelled spiral (red) in an unlabelled support hydrogel. Panel $\mathbf{a}$ is adapted from REF. ${ }^{32}$, CC-BY-4.0. Panel $\mathbf{b}$ is adapted from REF. ${ }^{33}$, CC-BY-4.0. Panel $\mathbf{c}$ is adapted with permission from REF. ${ }^{34}$, John Wiley and Sons.

3D tissue models have been developed, such as cellular spheroids, cell-laden hydrogel constructs, miniorgans and microfluidic organs-on-a-chip ${ }^{81,82}$; for example, in vitro models containing perfused microfluidic chambers and one cell type have been used. More complex systems can include multiple cell types organized along a porous membrane with integrated microchannels. However, most in vitro $3 \mathrm{D}$ models created by traditional methods such as biomedical microelectromechanical systems cannot recreate the dynamic, multicellular, spatially and functionally complex microscale architecture of tissues and organs ${ }^{83}$. To create a physiologically relevant 3D model platform, it is important to build tissue-like or organ-like miniatures that have similar structural and functional characteristics to native tissues.

\section{Bioprinted in vitro tissue models}

Skin. Bioprinting strategies can be employed to re-create multilayered skin tissue ${ }^{84-86}$. Layers of keratinocytes and fibroblasts can be bioprinted to construct a bioengineered skin tissue composed of epidermis and dermis, which can be used as an in vitro skin model. For example, a collagen hydrogel containing fibroblasts can be bioprinted, and melanocytes and keratinocytes can be sequentially deposited on top of the fibroblast layer to 
mimic the architecture of native skin ${ }^{84}$. A 3D human skin wound model can be engineered through the bioprinting of multilayered skin tissues on a non-planar PDMS surface $^{86}$. Such in vitro skin models can be used to study skin corrosion, irritation, permeability and the safety of chemical compounds.

Liver. Bioprinted hepatic models can serve as a platform for the investigation of physiological phenomena in the liver and for the accurate prediction of drug and toxic responses ${ }^{9,83,87-89}$. A liver micro-organ chamber device can be engineered by bioprinting a hepatocyte-laden alginate hydrogel in a microfluidic chamber, thereby creating a physiologically relevant pharmacokinetic model. This device can be operated at continuous perfusion flow while maintaining cell viability and hepatocyte-specific functions such as albumin and fibrinogen production. A human induced pluripotent stem cell (hiPSC)-laden alginate bioink can be bioprinted into a 3D mini-liver by the use of a dual-head jetting bioprinter ${ }^{7}$. The hiPSCs in the bioprinted construct were differentiated into hepatocytelike cells, which expressed hepatocyte-specific markers and secreted albumin. The function of 3D liver models can be evaluated through the analysis of protein synthesis (for example, fibrinogen and prothrombin), bile acid synthesis for digestion and the transformation of carbohydrates to fatty acids ${ }^{90-92}$.

Lung. In vitro 3D lung models have been considered for high-throughput screening and drug discovery ${ }^{93,94}$. A human in vitro air-blood barrier model, composed of three layers of endothelial cells, basement membrane and lung epithelial cells, can be fabricated using an extrusion-based bioprinter ${ }^{95}$. The $3 \mathrm{D}$ bioprinting process enables the construction of very thin and uniform layers of cells and Matrigel (as the basement membrane), which resemble the physiology and function of native lung tissue. A more realistic lung model can be achieved through introducing simulated physiological breathing motion by cyclic mechanical strain ${ }^{96}$.

Heart. Multimaterial bioprinting of sacrificial dextran, flexible thermoplastic polyurethane (TPU), conductive carbon black nanoparticles (CB) and PDMS allows for the creation of a cardiac microphysiological device ${ }^{5}$. In this device, TPU microfilaments guide cardiomyocyte alignment, and the deposited conductive CB-TPU composite is able to measure tissue contraction. Functional assessment of the in vitro cardiac tissue model includes cardiac cell synchronization, beating behaviour, electrophysiological properties and contractile force measurement ${ }^{97,98}$.

Kidney. An in vitro model of the human proximal tubule interstitial interface can be fabricated by bioprinting of renal fibroblasts, endothelial cells and primary human renal proximal tubule epithelial cells ${ }^{99}$. The in vitro proximal tubule tissue can be used to study the mechanisms of nephrotoxicity and to investigate epithelial-interstitial interactions involved in kidney pathogenesis.
Body-on-a-chip. Body-on-a-chip (or human-on-achip) devices aim to integrate multiple human tissue models within microfluidic devices ${ }^{100}$ to mimic human physiology. Bioprinting strategies ${ }^{101}$ can contribute to the development of such devices, for example, by providing a miniature $3 \mathrm{D}$ heart model that actively pumps fluid through the entire system and/or a 3D lung model to oxygenate, a 3D liver model to metabolize and a 3D kidney model to purify the circulating blood substitute.

Cancer models. In vitro 3D tumour models, such as cancer cell spheroids, are frequently used for therapeutic screening. Cellular spheroids mimic the cell-cell and cell-matrix interactions in the tumour microenvironment ${ }^{102,103}$. However, such models do not recapitulate all aspects of the complex tumour microenvironment, such as the associated vasculature and neural network. Therefore, bioprinting technology can be employed to create multicellular, controllable and reproducible tumour models. For example, a $3 \mathrm{D}$ cervical tumour model can be fabricated by the extrusion printing of HeLa cells (a human cell line derived from cervical cancer tissue $)^{104}$. Bioprinted cancer cells form spheroids in the $3 \mathrm{D}$ bioprinted microenvironment and exhibit high chemoresistance. A bioprinted ovarian tumour model that features a multicellular acini structure consisting of human ovarian cancer cells and normal fibroblasts can be engineered using inkjet bioprinting. This technique allows for precise control of cell density, droplet size and the spatial distance between the droplets. The bioprinted ovarian tumour model has been applied for high-throughput screening ${ }^{105}$. A breast tumour model can be created by the direct bioprinting of cell spheroids composed of breast cancer cells in the core, mammary fibroblasts and adipose cells into multi-well plates ${ }^{106}$. Such bioprinted tumour models provide an in vitro tool for the development of anticancer therapeutics.

\section{Bioassembled in vitro tissue models}

Bioassembly involves the integration of various-shaped cellular building blocks to reconstruct organomimetic macroscopic cellular tissues. Cell-laden hydrogels are commonly used as building blocks because their shapes can be varied using microfluidic and microfabrication techniques. Hydrogel-based building blocks are categorized into point-shaped, line-shaped and plane-shaped cell-laden structures ${ }^{107}$.

Point-shaped structures. Point-shaped cell-laden structures are easily prepared by culturing cells with hydrogel beads made of alginate ${ }^{108,109}, \mathrm{PEG}^{110,111}$ or collagen ${ }^{112,113}$. Such structures are fabricated using microfluidic devices with $\mathrm{T}$ junction, flow-focusing and nozzleshaped microchannels. Moulding is a popular method for the assembly of cell-laden beads. In this method, the beads are packed into a mould and integrated through cell adhesion, resulting in the construction of millimetre to centimetre-sized tissues with specific shapes defined by the shape of the mould ${ }^{108,111,112,114,115}$ (FIG. 5a). Moulding of point-shaped cell-laden structures 
a Point-shaped cell-laden structure

Cell-laden

beads

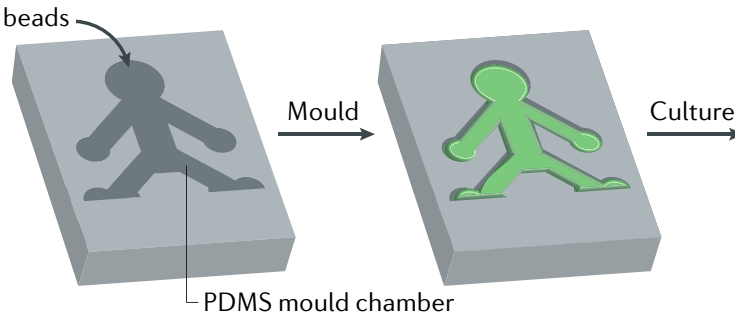

b Microfluidic manipulation
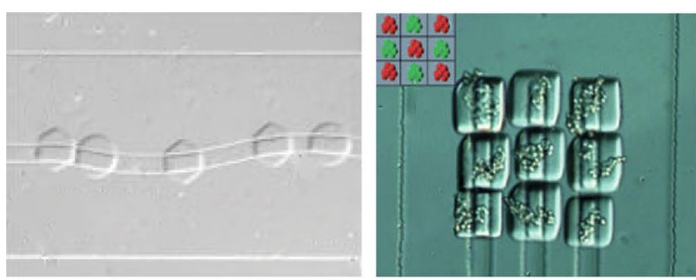

c Optically induced dielectrophoretic manipulation
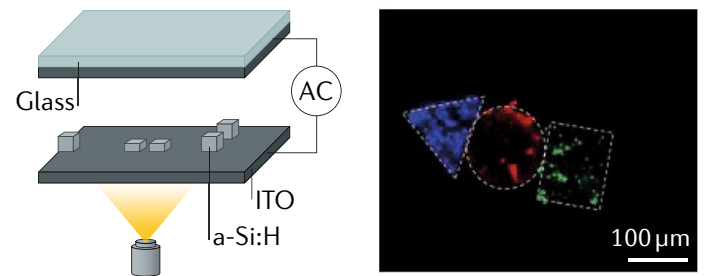

d Line-shaped cell-laden structure
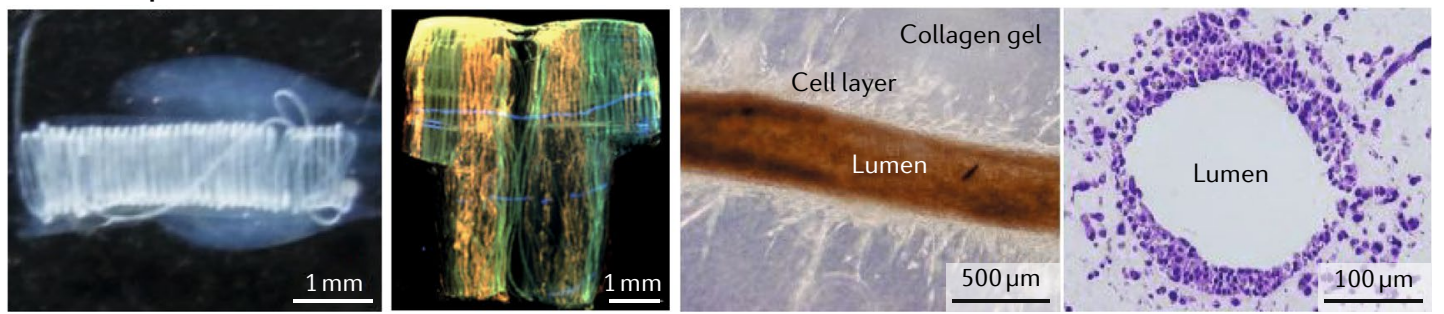

e Plane-shaped cell-laden structure
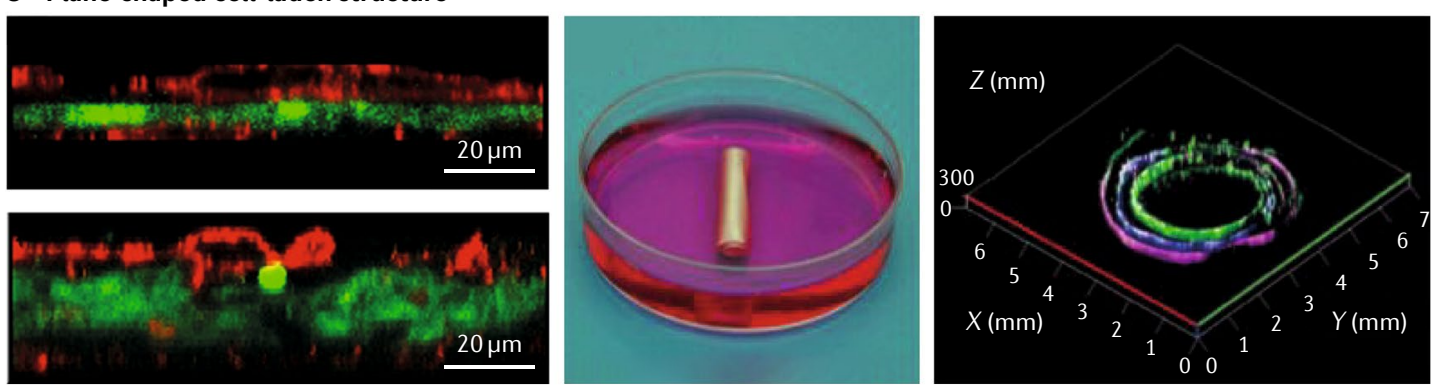

Fig. 5 | Bioassembly of macroscopic tissue structures. a | Cell-laden beads are assembled by moulding in poly(dimethylsiloxane). The microscopy image shows a human doll-shaped tissue made of fluorescently labelled fibroblasts (green) and collagen beads. b | Point-shaped cell-laden structures containing human epithelial cells transfected with green fluorescent protein and human embryonic kidney cells transfected with red fluorescent protein can be delivered and subsequently assembled by microfluidic flow. c | Optically induced dielectrophoretic force-based manipulation for the assembly of point-shaped cell-laden structures can also be used. The device consists of a top glass substrate with transparent and conductive indium oxide (ITO) coating, a working chamber and a bottom ITO glass substrate coated with a thin photoconductive hydrogenated amorphous silicon (a-Si:H) film. The microscopy image shows assembled point-shaped structures containing fibroblasts (green), human embryonic kidney cells (blue) and human metastatic mammary carcinoma cells (red). $\mathbf{d} \mid$ Assembly of line-shaped cell-laden structures is also used. Helical tubes are formed by reeling of a hepatocyte-laden and a fibroblast-laden fibre with a rod. A T-shirt-shaped structure is formed by weaving cell-laden fibres with fibroblasts (green), hepatocytes (red) and small lung carcinoma cells (blue). Blood vessellike structures can be fabricated by dissolving smooth muscle cell-laden and endothelial cell-laden alginate gel fibres in a collagen block. e | Assembly of plane-shaped cell-laden structures is also used. Cell-laden sheets are stacked by sandwiching a hepatocyte-laden sheet (green) between endothelial cell-laden sheets (red). Tubular structures are created by rolling of a cell-laden sheet containing endothelial cells (green), smooth muscle cells (blue) and fibroblasts (magenta). The tubular structure has multiple cell layers. Panel $\mathbf{a}$ is reproduced from REF. ${ }^{117}$, Macmillan Publishers Limited. Panel $\mathbf{b}$ is adapted with permission from REF. ${ }^{118}$, John Wiley and Sons. Panel $\mathbf{c}$ is adapted from REF. ${ }^{121}$, Macmillan Publishers Limited. Panel $\mathbf{d}$ is adapted with permission from REF. ${ }^{123}$, American Chemical Society. Panel e is adapted with permission from REFS ${ }^{128,129}$, John Wiley and Sons. 
has been applied for the construction of hepatic tissues $^{112}$, connective tissues ${ }^{112,115}$ and neural tissues ${ }^{114}$, for biological analyses in 3D culture conditions (for example, albumin secretion from hepatic tissue) and to investigate cell-cell interactions (for example, 3D neural networks). Organoids are point-shaped cell-laden structures that contain cellular aggregates of patientderived stem cells and possess diameters up to several millimetres. Organoids are promising macroscopic models for the physiologically relevant reconstruction of diseases ${ }^{116}$, and their assembly will be facilitated by bioassembly using moulds. Point-shaped cell-laden structures that contain different types of cells can be precisely arranged within macroscopic tissues by applying microfluidic and dielectrophoretic forces in microchannels in a high-throughput manner. This approach enables the spatial control of co-culture of different tissues ${ }^{117,118}$ (FIC. 5b,c).

Line-shaped structures. Line-shaped cell-laden structures, such as cell-laden fibres and tubes, are formed using laminar flow and nozzle-shaped microchannels, alginate $^{119,120}$ and/or collagen ${ }^{121,122}$. The assembly of cellladen fibres and tubes is facilitated through rotation of rods or plates at the outlet of the microchannels, allowing the reeling of fibres and tubes ${ }^{120,121}$. Using the reeling method, the different cell-laden fibres can be arranged on support structures in 3D (FIG. 5 d). Alternatively, weaving can be applied without support materials ${ }^{121}$. Using the weaving method, centimetre-sized 3D cellular tissues can be constructed on the basis of precisely arranged cell-laden fibres. For example, hepatic tissues can be formed through the reeling and weaving of hepatocyte-laden fibres and fibroblast-laden fibres. Such 3D co-culture conditions promote cellular functions (for example, albumin secretion). Furthermore, cell-laden fibres and tubes can be used to create lumen structures by embedding vascular endothelial cells in the fibres and tubes. The vascular channels, formed by the endothelial cells, provide nutrients and oxygen ${ }^{123,124}$ (FIG. 5d). The mechanical flexibility of cell-laden fibres and tubes allows for the formation of wavy-shaped vascular channels at arbitrary locations in the tissue. Thus, line-shaped cell-laden structures can be used as cellular building blocks for the construction of large-scale, 3D, vascularized tissues.

Plane-shaped structures. Plane-shaped cell-laden structures, for example, cell-laden sheets, can be fabricated using temperature-responsive culture dishes, microfluidic flat channels or sacrificial layers ${ }^{125-127}$. Stacking enables the assembly of cell-laden sheets, for example, to produce macroscopic hepatic tissues, in which hepatocyte-laden sheets are sandwiched between endothelial-laden sheets ${ }^{128}$ (FIG. 5e). Alternatively, rolling can be used to form tubular tissues. A cellular sheet containing precise arrangements of endothelial cells, smooth muscle cells and fibroblasts can be rolled up into a tube, resulting in a millimetre-sized hierarchical model of a vascular tube ${ }^{129,130}$ (FIG. 5 d). Such plane-shaped cell-laden structures can be applied for the construction of the cellular tissues with simple shapes.

\section{Tissue and organ regeneration}

Biofabrication strategies can be applied to create clinically applicable tissue constructs that can be implanted in the body. Biofabrication has the potential to engineer heterogeneous tissue structures, including shape-based tissues such as bone, cartilage, skin and cornea; organized tissues such as skeletal muscle and cardiac and neural tissues; composite tissues such as osteochondral and musculotendinous tissues; and whole organs with vasculature and functional inner structures such as the kidney and heart (FIG. 6). Biofabrication offers the opportunity to reconstruct the structural and ultimately the functional complexity of human tissues through incorporating materials, cells, biochemical and biophysical cues to specifically design tissue shape, organization, structure and integration.

\section{Shape}

Additive manufacturing technologies, such as direct metal laser sintering or electron beam melting, are already clinically in use, for example, for the fabrication of patient-specific metal implants ${ }^{131}$. Bioprinting technologies can be used to engineer patient-specific implants, for example, for bone grafting, and can take into account anatomic differences, defect size and patient-specific morphology of bone pathologies ${ }^{132-134}$. Furthermore, medical imaging techniques, such as computed tomography and magnetic resonance imaging can be applied to inform the customized design of personalized engineered tissues, for example, to fabricate bone constructs composed of osteoconductive materials such as hydroxyapatite and $\beta$-tricalcium phosphate as well as osteogenic cell types ${ }^{135-138}$. Similarly, heart valves, intervertebral discs and menisci can be constructed using biofabrication techniques ${ }^{139-141}$. The possibility to design personalized constructs constitutes a major strength of biofabrication technologies.

Current cartilage tissue engineering approaches can only partially recreate healthy and functional cartilage ${ }^{142}$ owing to difficulties in engineering the zonal differences in articular cartilage that have distinct cellular compositions ${ }^{143}$. Bioprinting can be applied to fabricate stratified cartilage constructs by regenerating the patient-specific size and shape of individual lesions $s^{144-148}$. Bioprinted cartilage exhibits similar biomechanical and biochemical properties to native cartilage and is well integrated with surrounding cartilage tissue as assessed by ECM deposition in vitro ${ }^{146}$. Auricular cartilage, for example, as found in the ear, can be reconstructed by an extrusion-based bioprinting process using sodium alginate, silver nanoparticles and chondrocytes arranged in an ear-shaped geometry around a conductive, sound-translating coil. This bionic ear can translate sound waves into an electrical output ${ }^{149}$. Furthermore, an extrusion-based bioprinting system has been applied to fabricate a human ear-shaped cartilage tissue construct ${ }^{138}$. The shape of the ear was well maintained for 2 months in a subcutaneous mouse model, as confirmed by glycosaminoglycan and collagen type II expression. Alternatively, chondrocyteladen alginate beads can be used for the construction of cartilage tissues. For example, chondrocyte-laden beads that are assembled with the shape of the cartilage 


\begin{tabular}{|c|c|c|c|}
\hline Design concept & Tissues and organs & Resolution & Applications \\
\hline Shape and size & $\begin{array}{l}\text { - Bone } \\
\text { - Ear } \\
\text { - Nose }\end{array}$ & $<400 \mu \mathrm{m}$ & \\
\hline $\begin{array}{l}\text { Tissue organization } \\
\text { (for example, } \\
\text { alignment) }\end{array}$ & $\begin{array}{l}\text { - Skeletal muscle } \\
\text { - Cardiac muscle }\end{array}$ & $<200-300 \mu \mathrm{m}$ & \\
\hline $\begin{array}{l}\text { Composite tissues } \\
\text { (for example, } \\
\text { interface) }\end{array}$ & $\begin{array}{l}\text { - Osteochondral tissue } \\
\text { - Musculotendinous } \\
\text { tissue }\end{array}$ & $<50-100 \mu \mathrm{m}$ & \\
\hline $\begin{array}{l}\text { Functional inner } \\
\text { structures } \\
\text { (for example, } \\
\text { vasculature, } \\
\text { nephron) }\end{array}$ & $\begin{array}{l}\text { - Microvasculature } \\
\text { - Nephron }\end{array}$ & $<10 \mu \mathrm{m}$ & \\
\hline
\end{tabular}

Fig. 6 | 3D bioprinting of tissues and organs. Biomedical applications based on design concept and printing resolution. Constructs of various shapes and sizes can be made: human-scale bone, ear-shaped and nose-shaped structures can be fabricated. At the level of tissue organization, cellular alignment can be achieved for skeletal and cardiac muscle constructs. Composite tissues, such as osteochondral (bone-cartilage) and musculotendinous (muscle-tendon), can be fabricated by sequentially patterning multiple components. Functional inner structures, such as microvasculature and nephrons, are required for whole organ bioprinting. The ear and skeletal muscle images are reproduced from REF. ${ }^{138}$, Macmillan Publishers Limited. The osteochondral tissue image is reproduced by permission from authors Francois Berthiaume and Jeffrey Morgan, 3D tissue engineering, Norwood, MA: Artech House, Inc., (2010). Copyright 2010 by Artech House, Inc. The musculotendinous tissue image is reproduced with permission from REF. ${ }^{163}$, IOP Publishing. The microvasculature image is reproduced with permission from REF. ${ }^{31}$, John Wiley and Sons. The nephron image is reproduced from REF. ${ }^{8}$, CC-BY-4.0.

defects in the knee can serve as grafts ${ }^{150,151}$. Skin is composed of thin layers of epidermis and dermis. In situ 3D bioprinting approaches can be applied to construct tissue replacements for large-scale skin wounds and burns, which have been successfully tested in mice ${ }^{152}$. In this approach, amniotic fluid-derived stem cells in a fibrinogen and collagen hydrogel are bioprinted over the wound area by the use of extrusion-based printing. This in situ skin bioprinting approach delivers cell-laden hydrogels directly onto the wound, achieving uniform wound coverage, thus providing an effective treatment for large-scale skin wounds.

Cornea also has a plane-shaped tissue structure composed of three layers: epithelium, stroma and endothelium. Corneal epithelial disorders caused by severe disease or trauma can result in corneal opacity and thus loss of visual acuity. Corneal epithelial cell sheets prepared by culturing limbal stem cells on a temperature-responsive culture dish can be directly placed onto the damaged tissue to reconstruct the corneal epithelium and to recover the transparency of the cornea ${ }^{153,154}$. Alternatively, oral mucosal epithelial cellladen sheets can be used for the treatment of bilateral corneal deficiency ${ }^{153,154}$.

\section{Tissue organization}

Skeletal muscle accounts for $\sim 40 \%$ of the human body weight ${ }^{155}$ and is composed of highly aligned muscle fibres. Fibre organization is essential for muscle contraction and force generation ${ }^{156}$. Extrusion-based printing can be applied to recreate the spatial organization of skeletal muscle fibres through the fabrication of micrometre-scale muscle-like bundles $(\sim 400 \mu \mathrm{m}$ in diameter $)^{138}$. The bioprinted muscle construct then matures into functional muscle tissue once integrated with the host nerves in vivo.

Similarly, cardiac tissue features complex myocardial organization to enable contractility ${ }^{97}$. Laser-induced forward transfer cell bioprinting can be applied to construct a cardiac patch exhibiting spatially organized patterns of human mesenchymal stromal cells (hMSCs) and endothelial cells on a poly(ester urethane) urea matrix ${ }^{157}$. Implantation of the cardiac patch into an infarcted rat heart promotes vascularization and improves cardiac function. A bioprinted, porous halfheart structure containing primary feline adult and $\mathrm{H} 1$ cardiomyocytes in alginate can be produced using a modified inkjet printing method ${ }^{158}$. The deposited cells retain their viability in the tissue construct and 
exhibit contractility upon electric stimulation in vitro. Human cardiac-derived cardiomyocyte progenitor cells can also be bioprinted, resulting in $\sim 90 \%$ cell viability and cardiac tissue maturation for 7 days in culture ${ }^{159}$. Multiple cell types, including hiPSC-derived cardiomyocytes, human smooth muscle cells and human endothelial cells, can be seeded into a bioprinted uniaxially oriented gelatin scaffold to produce an hiPSCderived cardiac muscle patch ${ }^{160}$. Similarly, bioassembly approaches can be applied for cardiac regeneration, for example, cardiomyocyte-laden, skeletal myoblast-laden or hMSC-laden sheets can be implanted into damaged rat hearts to improve cardiac performance ${ }^{153}$.

\section{Composite tissues}

Simple-shaped tissue constructs offer the opportunity to replace parts of damaged tissue. However, such engineered scaffolds cannot recreate complex composite tissue types ${ }^{161}$. An anatomically correct osteochondral tissue construct composed of PCL and hydroxyapatite can be engineered using bioprinting. The bioprinted osteochondral tissue can be implanted to repair the entire articular surface of a synovial joint in a rabbit model $^{162}$. The regeneration of musculotendinous tissue represents a different challenge because of its mechanical function. To recreate the composite nature of the tissue and to enable mechanical function, four different tissue components are bioprinted into an integrated muscletendon unit (MTU) construct ${ }^{163}$. The MTU construct is composed of mechanically heterogeneous polymeric materials that are elastic on the muscle side and stiffer on the tendon side. Additionally, cells are distributed in a tissue-specific manner, with myoblasts on the muscle side and fibroblasts on the tendon side. The cells maintain high cell viability and orientation and express genes associated with musculotendinous junctional tissue in vitro, demonstrating the possibility to bioprint a $3 \mathrm{D}$ heterogeneous tissue construct with localized biological and biomechanical characteristics.

\section{Inner structures}

The incorporation of microvascular networks and functional inner structures in bioengineered constructs is crucial for whole organ bioprinting ${ }^{164}$. The limit of oxygen and nutrient diffusion for cells to survive in vivo is $100-200 \mu \mathrm{m}\left(\right.$ REFS $\left.^{165-167}\right)$. Building a functional vasculature within $3 \mathrm{D}$ tissue constructs remains challenging. Microtubular structures can be created using microfluidics and patterns to guide tissue invasion and vascularization in vivo ${ }^{168,169}$. Bioprinting can be employed to create microchannels that contain layers of endothelial cells. A sacrificial material, such as carbohydrate glass, can be used to provide a template for printing. Once removed, a microchannel remains, which mimics vascular tissue; however, this tissue is limited in size owing to difficulties associated with direct perfusion ${ }^{36}$.

Alternatively, 3D tissue constructs can be prefabricated with vasculature and printed using multiple cell types and ECM proteins ${ }^{170,171}$. Human microvascular endothelial cells self-align inside printed biomaterialbased microchannels and form a confluent microvascular lining. Engineered vascular tubes fabricated by bioassembly of cell-laden sheets have been used for arterial bypass through anastomosis of the tubes ${ }^{172}$. However, connecting the vasculature to the host circulatory system remains a challenge ${ }^{173}$.

Functional inner structures, such as the nephron and hepatic lobules, can also be fabricated by bioprinting. For example, 3D human renal proximal tubular structures containing proximal tubular epithelial cells can be generated $^{8}$. The tubule-like structure is circumscribed by proximal tubule epithelial cells and actively perfused through the open lumen. The bioprinted epithelial barrier can be disrupted by introducing nephrotoxin or ciclosporin A.

The integration of nerves is essential to render bioengineered tissues functional in vivo. Neuron-laden collagen fibres can be used for the formation of neural tissues exhibiting pathways of aligned neurons in spatially distinct areas ${ }^{174}$. The neuron-laden collagen fibres can then be used to connect different brain regions, for example, the hippocampal-prefrontal and visual pathways.

\section{Tissue encapsulation}

Advances in biofabrication techniques and materials science have enabled the fabrication of complex tissue structures in vitro; however, translation to the clinic still faces challenges, such as the fibrotic encapsulation of implanted constructs due to the foreign body response, which results in protein deposition and often failure of the implant. Alginate-based and PEG-based hydrogels have the potential to mitigate the foreign body response $\mathrm{e}^{175-177}$. These hydrogels are semipermeable with a diffusion cut-off that shields the implant from the immune cells but enables nutrients, waste and cellsecreted products to pass through; for example, embedded hydrogel beads can be simply prepared and injected. Beads with diameters $>1.5 \mathrm{~mm}\left(\mathrm{REF}^{178}{ }^{178}\right.$ or triazolethiomorpholine dioxide modifications of alginate enable the suppression of the host immune response ${ }^{176,179}$.

Using this method, cells in the islets of Langerhans, which secrete insulin in response to the glucose concentration in the blood, can be combined with hydrogel beads and implanted to replace diabetic pancreatic islets $^{177-179}$. The hydrogel beads are used to protect the islet cells from the host immune response, and thus the tissue constructs maintain viable and secrete insulin for a long period of time in the body of the patient, even in case of xenotransplantation ${ }^{180,181}$. Alginate beads can also be integrated with hepatic tissue and implanted to provide continuous secretion of albumin in the body ${ }^{182,183}$. Alternative to beads, alginate gel fibres and sheets containing pancreatic tissue have been proposed as retrievable grafts owing to their single-unit and connected structures ${ }^{121,122,184,185}$. Pancreatic islets can also be combined with alginate gel fibres and sheets and can secrete insulin to regulate blood glucose levels.

\section{Challenges and opportunities}

Conventional bioprinting and bioassembly spur from additive manufacturing and self-assembly processes ${ }^{15}$. Despite the many advantages, there are still a few limitations that need to be addressed to achieve complex tissue regeneration and ultimately organ regeneration. 
a

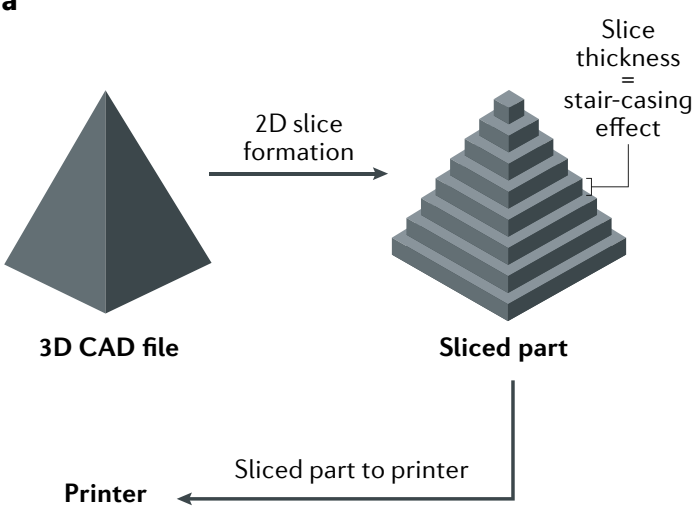

c

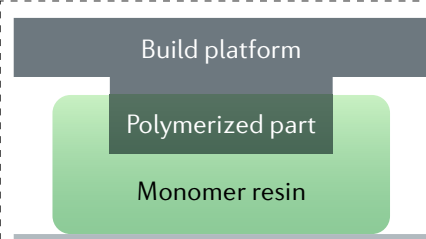

Oxygen-permeable window

Light source
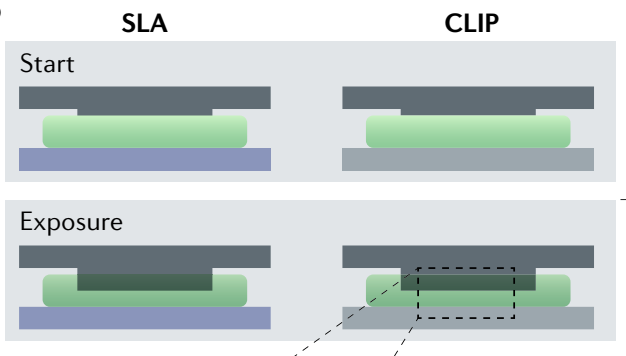

Separation
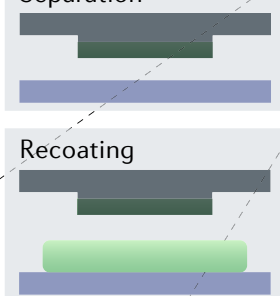

Repositioning

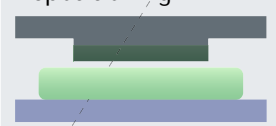

Final part

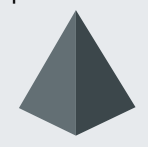

Fig. 7 | Stereolithography and continuous liquid interface production. a $\mid$ A 3D computer-aided design (CAD) file is first created for a given structure and then sliced. $\mathbf{b}$ |Continuous liquid interface production (CLIP) requires fewer steps than stereolithography (SLA) to assemble the designed structure. $c$ The fabrication process includes placement of the build elevator on the resin, subsequent UV exposure to selectively cure the resin, separation of the cured resin from the oxygenimpermeable window, mechanical recoating of the resin and, finally, repositioning of the build elevator to repeat the process until the part is fully printed. CLIP uses a constant liquid interface enabled by an oxygen-permeable window, which eliminates the need for the last three steps. Adapted with permission from REF. ${ }^{197}$, Proceedings of the National Academy of Sciences.

\section{Tissue complexity}

Progress in software design to control additive manufacturing systems has led to the implementation of scripts to calculate complex pore network architectures and multimaterial deposition. However, the majority of fabricated biological constructs are still characterized by simple architectures, which do not resemble the complexity of human tissues. Complex pore network architectures enable the recreation of functional mechanical properties, mimicking the mechanical behaviour of human tissues. For example, structures with variable Poisson ratios $^{186}$ lead to better vascular tissue regeneration than constructs with homogeneous contraction:relative expansion ratios ${ }^{54,187}$. Such engineered structures could be designed to enable large deformations ${ }^{188}$, storage of energy $^{189}$ or magnetic responsiveness ${ }^{190}$, endowing tissues with extended functionalities. Moreover, modelling can be applied to predict and design network organization of tissues and organs; for example, the vascular tree network can be modelled ${ }^{191,192}$ on the basis of theoretical cell aggregate fusion mechanisms ${ }^{193,194}$. Informing the experimental design of a given tissue construct through computational modelling will certainly improve the properties and function of biofabricated tissues.

\section{Scalability and manufacturing time}

Scalability and long manufacturing times of bioprinted constructs remain issues for clinical translation. Vat photopolymerization printing methods, such as stereolithography, digital light processing and continuous liquid interface production (CLIP), are additive manufacturing technologies based on photosensitive materials, which enable shorter lead fabrication times than other biofabrication technologies ${ }^{195-200}$. For example, CLIP allows for the fabrication of cubic centimetresized objects in minutes by controlling the amount of oxygen present at the interface between the photosensitive polymer and the light projector (FIG. 7). Therefore, the printing process is dependent only on the curing rate and viscosity of the polymer. The development of biomedical-grade photopolymers will pave the way for the bioprinting of large biological constructs using these additive manufacturing technologies.

\section{Levitation}

Bioacoustic levitation can be used to assemble cellladen constructs at high speed (FIG. 8). Bioacoustic printing enables the patterning of cell-laden hydrogels by applying Faraday waves ${ }^{201}$. The waves, when 
a

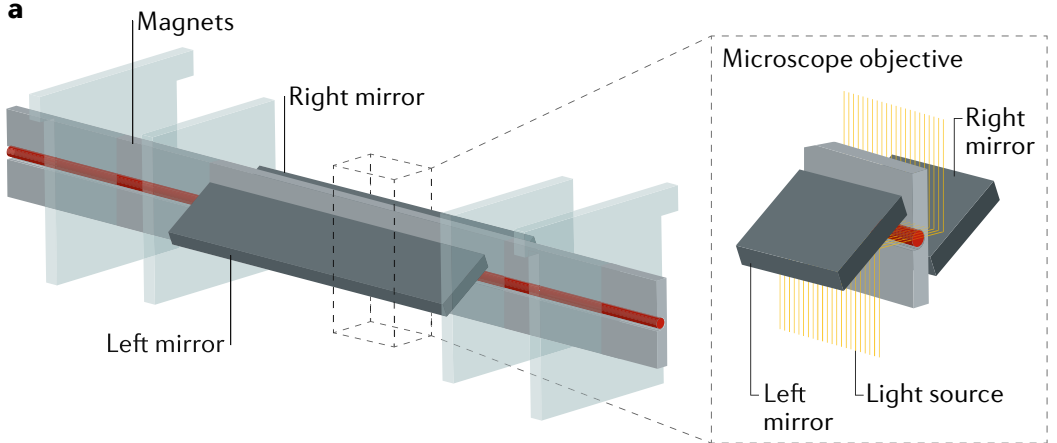

b

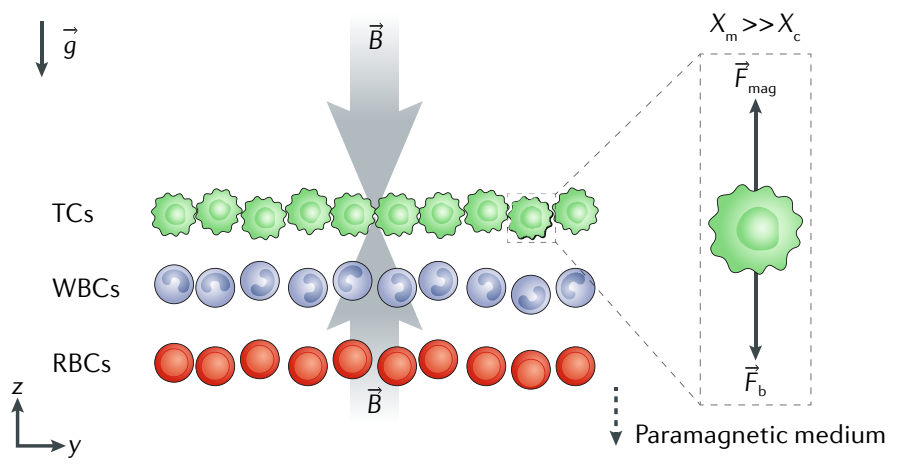

C

Bioacoustic levitational assembly
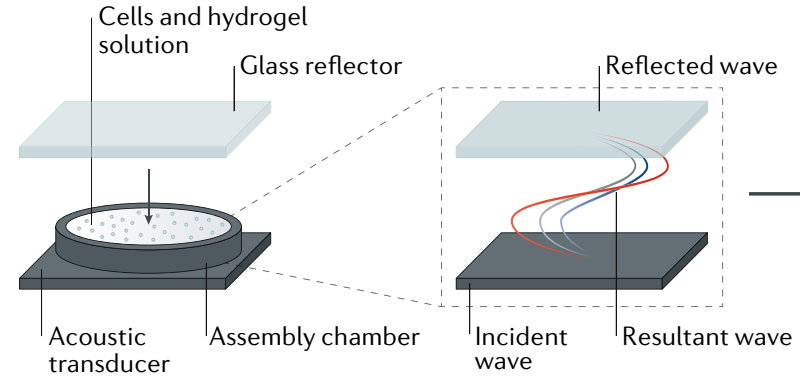

Neurodifferentiated multilayered construct
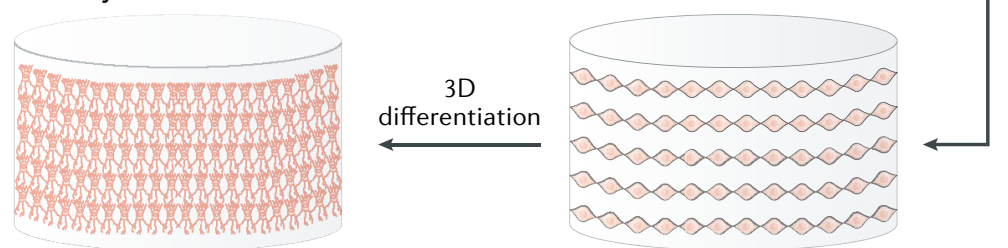

Fig. 8 | Bioacoustic levitation. a | A densitometry platform for the bioacoustic levitation of cells is shown. $\mathbf{b} \mid$ Owing to magnetic induction $(B)$ and gravity $(g)$, cells are levitated in the channel and focused in a plane in which magnetic forces $\left(F_{\text {mag }}\right)$ and buoyancy forces $\left(F_{\mathrm{b}}\right)$ are in equilibrium. The magnetic susceptibility of the medium $\left(X_{m}\right)$ has to be substantially larger than the magnetic susceptibility of the cells $\left(X_{c}\right)$, such that different cell types with different densities (tumour cells (TCs), white blood cells (WBCs) and red blood cells (RBCs)) can be separated. c A bioacoustic levitation bioprinting process to construct 3D neural constructs is shown. Neuroprogenitor cells in a fibrin hydrogel are placed in the levitation chamber. An acoustic ceramic generates incident waves, which coherently interfere with the waves reflected from the glass reflector, which is placed on top of the chamber. The resultant standing waves induce cells to levitate, resulting in 3D multilayer constructs of differentiated neural cells. Panels $\mathbf{a}$ and $\mathbf{b}$ are reproduced with permission from REF. ${ }^{203}$, Proceedings of the National Academy of Sciences. Panel $\mathbf{c}$ is adapted with permission from REF. ${ }^{202}$, John Wiley and Sons. coherently interfering with each other, can be used to initiate cell levitation in a resonant chamber containing a cell-laden hydrogel, enabling the deposition of cell layers in $<10$ seconds and thus the fabrication of constructs with high cell density (FIG. 8a). The deposited cells remain viable and proliferate for up to 7 days. However, fabrication times are an order of magnitude slower than those of conventional bioprinting technologies $^{202}$. Moreover, bioacoustic levitation is limited by the use of one single cell population and has thus far been used only with fibrin hydrogels ${ }^{201}$. Alternatively, magnetic levitation assembly can be used to manipulate different cell types ${ }^{203}$. Using this method, cells can be sorted by specific density in $3 \mathrm{D}$ through levitation in an equilibrium plane between magnetic and buoyancy forces. Cells remain viable for up to 5 days in vitro following magnetic levitation sorting. Levitation technologies could potentially be extended to enable the manipulation of hydrogels, which, in combination with other bioprinting approaches, would facilitate the fabrication of integrated systems, such as gel-in-gel and nanocolloidal systems ${ }^{32,33}$. However, validation of levitation technologies in longer in vitro studies and in animal models is necessary to assess the potential for therapeutic applications.

Levitation could further be used to assemble cellular aggregates or cell-laden microgels for the engineering of biological building blocks (FIG. 8b). Microgels provide a flexible platform because they can be synthesized with different built-in biological cues and cell types ${ }^{204}$. Furthermore, microgels allow for the fabrication of materials that have proved challenging to be processed, such as silicone, which might be relevant for fields such as soft robotics ${ }^{205}$. Cellular or cell-laden microgel building blocks can be self-assembled through cell-cell ${ }^{206}$ or secondary material interactions ${ }^{207}$. For example, DNA modification of these biological building blocks can trigger and program self-assembly a priori ${ }^{208,209}$. Alternatively, cell-laden microgels can be assembled into more complex structures by the use of magnetically actuated microrobotic systems ${ }^{210}$. Such microrobots contain magnetic materials that can be actuated by electromagnets, which are controlled by high-level user algorithms. The robots can apply forces of up to $70 \mathrm{nN}$ to pick and place PEG and GelMA cellladen hydrogels, and the incorporated cells maintain viability for up to 7 days after processing.

\section{Future perspective and conclusions}

Despite the rapid pace with which biofabrication strategies are being developed in different laboratories and companies worldwide, fabricating a fully functional tissue or organ is still beyond reach. Several challenges remain to produce functional organs for clinical applications and as therapeutic 3D models. Vascularization and innervation of engineered tissues will be key milestones for the construction and engraftment of functional constructs. Several strategies have already been explored to enable vascularization ${ }^{37,54}$, but only limited progress has been made in the design of innervation. Furthermore, the role of the immune system and the foreign body 
response needs to be fully elucidated to ensure functional engraftment upon implantation of biofabricated constructs $^{176,211,212}$. For the recreation of whole organs, a detailed biological understanding of tissue-specific cell populations and phenotypes is required to replicate the anatomy and physiology of the organ, including cell-cell and cell-ECM communication, as well as morphogenesis. For example, complex artificial niche-like environments in combination with two-photon polymerization enable fundamental studies of cell-ECM interactions at a submicrometre resolution ${ }^{213-215}$. Biological studies need to be accompanied by technological development to ultimately achieve a high degree of similarity between native tissues and organs and biofabricated constructs. Biomaterials need to be developed that mimic the dynamics of the ECM, for example, by exploiting hydrophilic and hydrophobic interactions ${ }^{216}$, electrical properties $^{217}$ or molecular self-assembly ${ }^{218}$. Experimental observations need to be coupled with multiparametric models of bioink viscosity to understand biomaterial behaviour during tissue fabrication. The fabrication of constructs comprising multiple materials, for example, by exploring microfluidic technologies ${ }^{219,220}$, will allow for the integration of different cell types and properties within one engineered tissue. Ultimately, the aim is to fabricate constructs that mimic native tissue organization ${ }^{221,222}$.

The deposition into or onto support materials enables bioprinting of materials that rapidly flow after extrusion. For example, a co-printed thermoplastic support framework into which soft materials can be deposited ${ }^{138,223}$ facilitates the fabrication of organ-scale constructs from soft materials. Liquid support systems, for example, the deposition of aqueous droplets into an oil reservoir ${ }^{216}$, can be applied for the bioprinting of materials with cells ${ }^{224}$. The immiscibility of the bioprinted ink with the oil support and the stabilization of the droplet by lipids in the oil phase enable the formation of stable, self-supported, droplet-based structures. By integrating low-gelling temperature agarose and cells in the aqueous ink, cooling can be used to trigger gelation, stabilizing the structure upon removal from the oil ${ }^{224}$.

The fabrication of macroscopic tissues and organs further requires a large number of cells, which are often challenging to obtain or produce. For generating large numbers of specialized and patient-specific cells, hiPSCs hold great potential, and biomaterials can provide an adequate, controlled environment for cell expansion and differentiation by dynamically displaying the correct biochemical and biophysical cues and by promoting cell viability ${ }^{225,226}$.
Simple tissue defects can already be treated with biofabricated scaffolds exhibiting hierarchical structural properties or engineered surface properties to steer cell activity. However, complex biofabricated constructs require maturation in bioreactors and cannot yet be directly implanted in patients after fabrication. Technologies need to be developed to monitor and control the behaviour of processed cells, the maturation of assembled tissues and physicochemical changes, such as shrinking, swelling, deformation and degradation, that occur in the supporting biomaterials during the fabrication and maturation process. Adhesion, migration, proliferation, differentiation and apoptosis of cells also need to be monitored and, ideally, controlled, and the biological building blocks need to be correctly combined, fixed and connected in 3D. For example, impedance measurements of integrated carbon nanotubes allow for the monitoring of cell adhesion, spreading and density in $3 \mathrm{D}^{227}$. Similarly, sol-gel formulations, fabricated by inkjet printing, enable the integration of $\mathrm{pH}$ sensors into cell-laden hydrogels ${ }^{228}$. Tissue maturation can be followed by assessing functional markers in real time, for example, by integrating biofabrication technologies with electronically active biomaterials or materials with intrinsic optoelectronic properties ${ }^{229,230}$.

Tissues can also be regenerated in situ by the use of biomaterials that actively trigger the regeneration process, for example, for musculoskeletal ${ }^{231,232}$ and cardiovascular ${ }^{233,234}$ applications, possibly in combination with biofabrication strategies ${ }^{235}$. The development of dynamic materials (for example, shape memory materials or supramolecular hydrogels) compatible with bioprinting will facilitate $4 \mathrm{D}$ printing ${ }^{236}$, exploiting temporal external stimuli during processing or after implantation $^{237}$.

The biofabrication and medical application of a fully functional organ will depend on fruitful collaborations across many disciplines, encompassing engineering, materials science, biology, medicine and business administration, to ensure not only progress in fundamental science but also clinical translation through commercialization. The biofabrication community has already developed tissue constructs for preclinical models and is working towards upscaling to human-scale tissues. We envision that tissues such as biofabricated skin, cartilage and vascular and cardiac patches, as well as peripheral neural grafts, have the potential to reach the clinic within the next 5-10 years.

Published online: 26 April 2018
1. Gomes, M. E., Rodrigues, M. T., Domingues, R. M. A $\&$ Reis, R. L. Tissue engineering and regenerative medicine: new trends and directions-a year in review. Tissue Eng. Part B Rev. 23, 211-224 (2017).

2. Tschugg, A. et al. A prospective randomized multicenter phase I/II clinical trial to evaluate safety and efficacy of NOVOCART disk plus autologous disk chondrocyte transplantation in the treatment of nucleotomized and degenerative lumbar disks to avoid secondary disease: safety results of Phase I-a short report. Neurosurg. Rev. 40, 155-162 (2017).
3. Martin, I. et al. The survey on cellular and engineered tissue therapies in Europe in 2013. Tissue Eng. A 22, 5-16 (2016).

4. Groll, J. et al. Biofabrication: reappraising the definition of an evolving field. Biofabrication 8, 013001 (2016).

5. Lind, J. U. et al. Instrumented cardiac microphysiological devices via multimaterial threedimensional printing. Nat. Mater. 16, 303-308 (2017).

6. Dai, X. et al. Coaxial 3D bioprinting of self-assembled multicellular heterogeneous tumor fibers. Sci. Rep. 7, 1457 (2017).
7. Faulkner-Jones, A. et al. Bioprinting of human pluripotent stem cells and their directed differentiation into hepatocyte-like cells for the generation of mini-livers in 3D. Biofabrication 7, 044102 (2015).

8. Homan, K. A. et al. Bioprinting of 3D convoluted renal proximal tubules on perfusable chips. Sci. Rep. 6, 34845 (2016)

9. Jeon, H. et al. Generation of multilayered 3D structures of HepG 2 cells using a bio-printing technique. Gut Liver 11, 121-128 (2017). 
10. Burdick, J. A. \& Murphy, W. L. Moving from static to dynamic complexity in hydrogel design. Nat. Commun. 3, $1269(2012)$

11. Gobaa, S. et al. Artificial niche microarrays for probing single stem cell fate in high throughput. Nat. Methods 8, 949-955 (2011).

12. Lutolf, M. P. \& Hubbell, J. A. Synthetic biomaterials as instructive extracellular microenvironments for morphogenesis in tissue engineering. Nat. Biotechnol. 23, 47 (2005).

13. Tibbitt, M. W. \& Anseth, K. S. Hydrogels as extracellular matrix mimics for 3D cell culture. Biotechnol. Bioeng. 103, 655-663 (2009).

14. Khetan, S. \& Burdick, J. A. Patterning hydrogels in three dimensions towards controlling cellular interactions. Soft Matter 7, 830-838 (2011).

15. Moroni, L. et al. Biofabrication: a guide to technology and terminology. Trends Biotechnol. 36, 384-402 (2018).

16. Jungst, T., Smolan, W., Schacht, K., Scheibel, T. \& Groll, J. Strategies and molecular design criteria for 3D printable hydrogels. Chem. Rev. 116, 1496-1539 (2016).

17. Guvendiren, M., Molde, J., Soares, R. M. \& Kohn, J. Designing biomaterials for 3D printing. ACS Biomater Sci. Eng. 2, 1679-1693 (2016).

18. Ligon, S. C., Liska, R., Stampfl, J., Gurr, M. \& Mulhaupt, R. Polymers for 3D printing and customized additive manufacturing. Chem. Rev. 117 10212-10290 (2017).

19. Shi, W. et al. Structurally and functionally optimized silk-fibroin-gelatin scaffold using 3D printing to repair cartilage injury in vitro and in vivo. Adv. Mater. 29, 1701089 (2017)

20. Levato, R. et al. The bio in the ink: cartilage regeneration with bioprintable hydrogels and articular cartilage-derived progenitor cells. Acta Biomater. 61 , 41-53 (2017).

21. Compaan, A. M., Christensen, K. \& Huang, Y. Inkjet bioprinting of 3D silk fibroin cellular constructs using sacrificial alginate. ACS Biomater. Sci. Eng. (2016).

22. Colosi, C. et al. Microfluidic bioprinting of heterogeneous 3D tissue constructs using lowviscosity bioink. Adv. Mater. 28, 677-684 (2016).

23. Ouyang, L., Highley, C. B., Sun, W. \& Burdick, J. A. A Generalizable strategy for the 3D bioprinting of hydrogels from nonviscous photo-crosslinkable inks. Adv. Mater. 29, 1604983 (2017)

24. Liu, W. et al. Rapid continuous multimaterial extrusion bioprinting. Adv. Mater. 29, 1604630 (2017).

25. Schacht, K. et al. Biofabrication of cell-loaded 3D spider silk constructs. Angew. Chem. Int. Ed. 54, 2816-2820 (2015)

26. Ouyang, L. L., Highley, C. B., Rodell, C. B., Sun, W. \& Burdick, J. A. 3D printing of shear-thinning hyaluronic acid hydrogels with secondary cross-linking. ACS Biomater. Sci. Eng. 2, 1743-1751 (2016).

27. Li, C. et al. Rapid formation of a supramolecular polypeptide-dna hydrogel for in situ threedimensional multilayer bioprinting. Angew. Chem Int. Ed. 54, 3957-3961 (2015).

28. Dubbin, K., Hori, Y., Lewis, K. K. \& Heilshorn, S. C Dual-stage crosslinking of a gel-phase bioink improves cell viability and homogeneity for 3D bioprinting. Adv. Healthc. Mater. 5, 2488-2492 (2016).

29. Loo, Y. \& Hauser, C. A. E. Bioprinting synthetic self-assembling peptide hydrogels for biomedical applications. Biomed Mater 11, 014103 (2015).

30. Landers, R., Hübner, U., Schmelzeisen, R. \& Mülhaupt, R. Rapid prototyping of scaffolds derived from thermoreversible hydrogels and tailored for applications in tissue engineering. Biomaterials 23, 4437-4447 (2002).

31. Wu, W., DeConinck, A. \& Lewis, J. A. Omnidirectional printing of 3D microvascular networks. Adv. Mater. 23 H178-H183 (2011)

32. Hinton, T. J. et al. Three-dimensional printing of complex biological structures by freeform reversible embedding of suspended hydrogels. Sci. Adv. 1 , e 1500758 (2015).

33. Bhattacharjee, T. et al. Writing in the granular gel medium. Sci. Adv. 1, e1500655 (2015).

34. Highley, C. B., Rodell, C. B. \& Burdick, J. A Direct 3D printing of shear-thinning hydrogels into self-healing hydrogels. Adv. Mater. 27, 5075-5079 (2015).

35. Shi, L. et al. Dynamic coordination chemistry enables free directional printing of biopolymer hydrogel. Chem. Mater. 29, 5816-5823 (2017).

36. Miller, J. S. et al. Rapid casting of patterned vascular networks for perfusable engineered 3D tissues. Nat. Mater. 11, 768 (2012).
37. Kolesky, D. B., Homan, K. A., Skylar-Scott, M. A. \& Lewis, J. A. Three-dimensional bioprinting of thick vascularized tissues. Proc. Natl Acad. Sci. USA 113, 3179-3184 (2016).

38. Bhattacharjee, T. et al. Liquid-like solids support cells in 3D. ACS Biomater. Sci. Eng. 2, 1787-1795 (2016).

39. Mironov, V. et al. Organ printing: tissue spheroids as building blocks. Biomaterials 30, 2164-2174 (2009).

40. Sego, T. J., Kasacheuski, U., Hauersperger, D., Tovar, A $\&$ Moldovan, N. I. A heuristic computational model of basic cellular processes and oxygenation during spheroid-dependent biofabrication. Biofabrication 9 , 024104 (2017).

41. Bakirci, E., Toprakhisar, B., Zeybek, M., Ozaydin, I. G. $\&$ Koc, B. Cell sheet based bionk for 3D bioprinting applications. Biofabrication 9, 024105 (2017).

42. Owaki, T., Shimizu, T., Yamato, M. \& Okano, T. Cell sheet engineering for regenerative medicine: current challenges and strategies. Biotechnol. J. 9, 904-914 (2014).

43. Roh, S., Parekh, D. P., Bharti, B., Stoyanov, S. D. \& Velev, O. D. 3D printing by multiphase silicone/water capillary inks. Adv. Mater. 29, 1701554 (2017).

44. Rutz, A. L., Hyland, K. E., Jakus, A. E., Burghardt, W. R. $\S$ Shah, R. N. A multimaterial bioink method for 3D printing tunable, cell-compatible hydrogels. Adv. Mater 27, 1607-1614 (2015)

45. Rosales, A. M. \& Anseth, K. S. The design of reversible hydrogels to capture extracellular matrix dynamics. Nat Rev Mater 1, 15012 (2016).

46. Fairbanks, B. D. et al. A versatile synthetic extracellular matrix mimic via thiol-norbornene photopolymerization. Adv. Mater. 21, 5005-5010 (2009)

47. Stichler, S. et al. Thiol-ene clickable poly(glycidol) hydrogels for biofabrication. Ann. Biomed. Eng. 45 273-285 (2017)

48. Stichler, S., Bertlein, S., Tessmar, J., Jungst, T. \& Groll, J. Thiol-ene cross-linkable hydrogels as bioinks for biofabrication. Macromol. Symp. 372, 102-107 (2017)

49. Bertlein, S. et al. Thiol-ene clickable gelatin: a platform bioink for multiple 3D biofabrication technologies. Adv. Mater. 29, 1703404 (2017).

50. Yeh, Y.-C., Ouyang, L., Highley, C. B. \& Burdick, J. A Norbornene-modified poly (glycerol sebacate) as a photocurable and biodegradable elastomer. Polym. Chem. 8, 5091-5099 (2017).

51. Mondschein, R. J., Kanitkar, A., Williams, C. B. Verbridge, S. S. \& Long, T. E. Polymer structureproperty requirements for stereolithographic 3D printing of soft tissue engineering scaffolds. Biomaterials 140, 170-188 (2017)

52. Vitale, A. et al. Oxygen-inhibition lithography for the fabrication of multipolymeric structures. Adv. Mater 27, 4560-4565 (2015)

53. Zhang, A. P. et al. Rapid fabrication of complex 3D extracellular microenvironments by dynamic optical projection stereolithography. Adv. Mater. 24 4266-4270 (2012).

54. Zhu, W. et al. Direct 3D bioprinting of prevascularized tissue constructs with complex microarchitecture. Biomaterials 124, 106-115 (2017).

55. Brandenberg, N. \& Lutolf, M. P. In situ patterning of microfluidic networks in 3D cell-laden hydrogels. Adv. Mater. 28, 7450-7456 (2016).

56. Arakawa, C. K., Badeau, B. A., Zheng, Y. \& DeForest, C. A. Multicellular vascularized engineered tissues through user-programmable biomaterial photodegradation. Adv. Mater. 29, 1703156 (2017).

57. Mouser, V. H. et al. Development of a thermosensitive HAMA-containing bio-ink for the fabrication of composite cartilage repair constructs. Biofabrication 9, 015026 (2017)

58. Rhee, S., Puetzer, J. L., Mason, B. N. Reinhart-King, C. A. \& Bonassar, L. J. 3D bioprinting of spatially heterogeneous collagen constructs for cartilage tissue engineering. ACS Biomater. Sci. Eng. 2, 1800-1805 (2016)

59. Diamantides, N. et al. Correlating rheological properties and printability of collagen bioinks: the effects of riboflavin photocrosslinking and $\mathrm{pH}$. Biofabrication 9, 034102 (2017).

60. Bolaños, R. A. V. et al. The use of a cartilage decellularized matrix scaffold for the repair of osteochondral defects: the importance of long-term studies in a large animal model. Osteoarthritis Cartilage 25, 413-420 (2017).

61. Pati, F. et al. Printing three-dimensional tissue analogues with decellularized extracellular matrix bioink. Nat. Commun. 5, 3935 (2014)

62. Kim, B. S., Kim, H., Gao, G., Jang, J. \& Cho, D. W. Decellularized extracellular matrix: a step towards the next generation source for bioink manufacturing Biofabrication 9, 034104 (2017).

63. Levato, R. et al. The bio in the ink: cartilage regeneration with bioprintable hydrogels and articula cartilage-derived progenitor cells. Acta Biomaterialia (2017).

64. Shi, W. et al. Structurally and functionally optimized silk-fibroin-gelatin scaffold using 3D printing to repair cartilage injury in vitro and in vivo. Adv. Mater. 29 , 1701089 (2017).

65. Klotz, B. J., Gawlitta, D., Rosenberg, A. J. W. P. Malda, J. \& Melchels, F. P. W. Gelatin-methacryloyl hydrogels: towards biofabrication-based tissue repair. Trends Biotechnol. 34, 394-407 (2016).

66. Khalil, S. \& Sun, W. Bioprinting endothelial cells with alginate for 3D tissue constructs. J. Biomech. Eng. 131, 111002 (2009).

67. Duan, B., Hockaday, L. A., Kang, K. H. \& Butcher, J. T. 3D bioprinting of heterogeneous aortic valve conduits with alginate/gelatin hydrogels. J. Biomed. Mater. Res. A 101, 1255-1264 (2013).

68. Jose, R. R., Brown J. E. Polido, K. E. Omenetto, F. C. \& Kaplan, D. L. Polyol-silk bioink formulations as two-part room-temperature curable materials for 3D printing. ACS Biomater. Sci. Eng. 1, 780-788 (2015).

69. Sommer, M. R., Schaffner, M., Carnelli, D \& Studart, A. R. 3D printing of hierarchical silk fibroin structures. ACS Appl. Mater. Inter 8, 34677-34685 (2016).

70. Badylak, S. F., Taylor, D. \& Uygun, K. Whole-organ tissue engineering: decellularization and recellularization of three-dimensional matrix scaffolds. Annu. Rev. Biomed. Eng. 13, 27-53 (2011).

71. Cheng, J. et al. Rheological properties of cell-hydroge composites extruding through small-diameter tips. J. Manuf. Sci. Eng. 130, 021014 (2008).

72. Xu, C. X. et al. Study of droplet formation process during drop-on-demand inkjetting of living cell-laden bioink. Langmuir 30, 9130-9138 (2014).

73. Zhang, Z. Y., Xu, C. X., Xiong, R. T., Chrisey, D. B. \& Huang, Y. Effects of living cells on the bioink printability during laser printing. Biomicrofluidics $\mathbf{1 1}$, (2017).

74. Nussinovitch, A. Resemblance of immobilized trichoderma-viride fungal spores in an alginate matrix to a composite-material. Biotechnol. Progr. 10 551-554 (1994).

75. Zhang, X. Z. \& Chu, C. C. Fabrication and characterization of microgel-impregnated thermosensitive PNIPAAm hydrogels. Polymer 46 9664-9673 (2005)

76. Lim, C. T. Zhou, E. H \& Quek, S. T. Mechanical models for living cells - a review. J. Biomech. 39 195-216 (2006).

77. Mekhileri, N. V. et al. Automated 3D bioassembly of micro-tissues for biofabrication of hybrid tissue engineered constructs. Biofabrication 10, (2018).

78. Yeo, M., Lee, J. S., Chun, W. \& Kim, G. H. An innovative collagen-based cell-printing method for obtaining human adipose stem cell-laden structures consisting of core sheath structures for tissue engineering. Biomacromolecules 17, 1365-1375 (2016).

79. Levato, R. et al. Biofabrication of tissue constructs by 3D bioprinting of cell-laden microcarriers. Biofabrication 6, (2014).

80. Kamperman, T. et al. Single cell microgel based modular bioinks for uncoupled cellular micro- and macroenvironments. Adv. Healthc. Mater. 6, (2017).

81. Bhatia, S. N. \& Ingber, D. E. Microfluidic organson-chips. Nat. Biotechnol. 32, 760-772 (2014).

82. Cohen, D. L., Malone, E., Lipson, H. \& Bonassar, L. J. Direct freeform fabrication of seeded hydrogels in arbitrary geometries. Tissue Eng. 12, 1325-1335 (2006).

83. Pati, F., Gantelius, J. \& Svahn, H. A. 3D bioprinting of tissue/organ models. Angew. Chem. Int. Ed. 55 , 4650-4665 (2016)

84. Min, D. et al. Bioprinting of biomimetic skin containing melanocytes. Exp. Dermatol. https://doi. org/10.1111/exd.13376 (2017)

85. Lee, V. et al. Design and fabrication of human skin by three-dimensional bioprinting. Tissue Eng. C 20 , 473-484 (2014).

86. Lee, W. et al. Multi-layered culture of human skin fibroblasts and keratinocytes through threedimensional freeform fabrication. Biomaterials 30 1587-1595 (2009)

87. Mandrycky, C., Wang, Z., Kim, K. \& Kim, D. H. 3D bioprinting for engineering complex tissues. Biotechnol. Adv. 34, 422-434 (2016). 
88. Ozbolat, I. T., Peng, W. \& Ozbolat, V. Application areas of 3D bioprinting. Drug Discov. Today 21 1257-1271 (2016)

89. Arslan-Yildiz, A. et al. Towards artificial tissue models: past, present, and future of 3D bioprinting. Biofabrication 8, 014103 (2016).

90. Vyas, D. et al. Self-assembled liver organoids recapitulate hepatobiliary organogenesis in vitro. Hepatology 67, 750-761 (2017)

91. Bhise, N. S. et al. A liver-on-a-chip platform with bioprinted hepatic spheroids. Biofabrication 8, 014101 (2016).

92. Knowlton, S. \& Tasoglu, S. A. Bioprinted liver-on-a-chip for drug screening applications. Trends Biotechnol. 34, 681-682 (2016)

93. Konar, D., Devarasetty, M., Yildiz, D. V., Atala, A. \& Murphy, S. V. Lung-on-a-chip technologies for disease modeling and drug development. Biomed. Eng. Comput. Biol. 7, 17-27 (2016)

94. Doryab, A., Amoabediny, G. \& Salehi-Najafabadi, A Advances in pulmonary therapy and drug development: lung tissue engineering to lung-on-achip. Biotechnol. Adv. 34, 588-596 (2016).

95. Horvath, L. et al. Engineering an in vitro air-blood barrier by 3D bioprinting. Sci. Rep. 5, 7974 (2015).

96. Huh, D. et al. Reconstituting organ-level lung functions on a chip. Science 328, 1662-1668 (2010).

97. Wang, Z., Lee, S. J., Cheng, H. J., Yoo, J. J. \& Atala, A. 3D bioprinted functional and contractile cardiac tissue constructs. Acta Biomater. https://doi.org/10.1016/j. actbio.2018.02.007 (2018)

98. Zhang, Y. S. et al. Bioprinting 3D microfibrous scaffolds for engineering endothelialized myocardium and heart-on-a-chip. Biomaterials 110, 45-59 (2016).

99. King, S. M. et al. 3D proximal tubule tissues recapitulate key aspects of renal physiology to enable nephrotoxicity testing. Front. Physiol. 8, 123 (2017).

100. Abaci, H. E. \& Shuler, M. L. Human-on-a-chip design strategies and principles for physiologically based pharmacokinetics/pharmacodynamics modeling. Integr. Biol. 7, 383-391 (2015).

101. Skardal, A. et al. Multi-tissue interactions in an integrated three-tissue organ-on-a-chip platform. Sci. Rep. 7, 8837 (2017).

102. Weiswald, L. B., Bellet, D. \& Dangles-Marie, V. Spherical cancer models in tumor biology. Neoplasia 17, 1-15 (2015)

103. Skardal, A., Devarasetty, M., Rodman, C., Atala, A. $\&$ Soker, S. Liver-tumor hybrid organoids for modeling tumor growth and drug response in vitro. Ann. Biomed. Eng. 43, 2361-2373 (2015)

104. Friedrich, J., Ebner, R. \& Kunz-Schughart, L. A. Experimental anti-tumor therapy in 3D: spheroids old hat or new challenge? Int. J. Radiat. Biol. 83, 849-871 (2007)

105. Xu, F. et al. A three-dimensional in vitro ovarian cancer coculture model using a high-throughput cell patterning platform. Biotechnol. J. 6, 204-212 (2011)

106. King, S. M., Presnell, S. C. \& Nguyen, D. G. Development of 3D bioprinted human breast cancer for in vitro drug screening. Cancer Res. 74 (Suppl), 2034 (2014).

107. Morimoto, Y., Hsiao, A. Y. \& Takeuchi, S. Point-, lineand plane-shaped cellular constructs for 3D tissue assembly. Adv. Drug Deliv. Rev. 95, 29-39 (2015).

108. Morimoto, Y., Onuki, M. $\&$ Takeuchi, S. Mass production of cell-laden calcium alginate particles with centrifugal force. Adv. Healthc. Mater. 6, 1601375 (2017).

109. Tan, W. H. \& Takeuchi, S. Monodisperse alginate hydrogel microbeads for cell encapsulation. Adv. Mater. 19, 2696-2701 (2007)

110. Headen, D. M., Aubry, G., Lu, H. \& Garcia, A. J. Microfluidic-based generation of size-controlled, biofunctionalized synthetic polymer microgels for cell encapsulation. Adv. Mater. 26, 3003-3008 (2014).

111. Griffin, D. R., Weaver, W. M., Scumpia, P. O., Di Carlo, D. $\&$ Segura, T. Accelerated wound healing by injectable microporous gel scaffolds assembled from annealed building blocks. Nat. Mater. 14, 737-744 (2015).

112. Matsunaga, Y. T., Morimoto, Y. \& Takeuchi, S. Molding cell beads for rapid construction of macroscopic 3D tissue architecture. Adv. Mater. 23, H90-H94 (2011).

113. Hong, S. M., Hsu, H. J., Kaunas, R. \& Kameoka, J. Collagen microsphere production on a chip. Lab. Chip 12, 3277-3280 (2012)

114. Kato-Negishi, M., Morimoto, Y., Onoe, H. \& Takeuchi, S Millimeter-sized neural building blocks for 3D heterogeneous neural network assembly. Adv. Healthc. Mater. 2, 1564-1570 (2013)

115. Luo, H. Y. et al. Fabrication of viable centimeter-sized 3D tissue constructs with microchannel conduits for improved tissue properties through assembly of cell- laden microbeads. J. Tissue Eng. Regen. Med. 8, 493-504 (2014).

116. Dutta, D., Heo, I. \& Clevers, H. Disease modeling in stem cell-derived 3D organoid systems. Trends Mol. Med. 23, 393-410 (2017).

117. Chung, S. E., Park, W., Shin, S., Lee, S. A. \& Kwon, S. Guided and fluidic self-assembly of microstructures using railed microfluidic channels. Nat. Mater. 7 , 581-587 (2008)

118. Yang, W., Yu, H., Li, G., Wang, Y. \& Liu, L. Highthroughput fabrication and modular assembly of 3D heterogeneous microscale tissues. Small 13 1602769 (2017)

119. Kang, E. et al. Digitally tunable physicochemical coding of material composition and topography in continuous microfibres. Nat. Mater. 10, 877-883 (2011).

120. Wei, D. et al. Continuous fabrication and assembly of spatial cell-laden fibers for a tissue-like construct via a photolithographic-based microfluidic chip. ACS Appl. Mater. Inter 9, 14606-14617 (2017).

121. Onoe, H. et al. Metre-long cell-laden microfibres exhibit tissue morphologies and functions. Nat. Mater. 12, 584-590 (2013).

122. Jun, Y. et al. Microfluidics-generated pancreatic islet microfibers for enhanced immunoprotection. Biomaterials 34, 8122-8130 (2013).

123. Sakai, S., Yamaguchi, S., Takei, T \& Kawakami, K. Oxidized alginate-cross-linked alginate/gelatin hydrogel fibers for fabricating tubular constructs with layered smooth muscle cells and endothelial cells in collagen gels. Biomacromolecules 9, 2036-2041 (2008).

124. Lee, K. H., Shin, S. J., Park, Y. \& Lee, S. H. Synthesis of cell-laden alginate hollow fibers using microfluidic chips and microvascularized tissue-engineering applications. Small 5, 1264-1268 (2009).

125. Yang, J. et al. Cell sheet engineering: recreating tissues without biodegradable scaffolds. Biomaterials 26, 6415-6422 (2005)

126. Leng, L., McAllister, A., Zhang, B. Y., Radisic, M. \& Gunther, A. Mosaic hydrogels: one-step formation of multiscale soft materials. Adv. Mater. 24, 3650-3658 (2012).

127. Yan, J., Chen, F. \& Amsden, B. G. Cell sheets prepared via gel-sol transition of calcium RGD-alginate. Acta Biomaterialia 30, 277-284 (2016)

128. Kim, K., Utoh, R., Ohashi, K., Kikuchi, T. \& Okano, T. Fabrication of functional 3D hepatic tissues with polarized hepatocytes by stacking endothelial cell sheets in vitro. J. Tissue Eng. Regen. Med. 11, 2071-2080 (2017)

129. Cheng, S. et al. Self-adjusting, polymeric multilayered roll that can keep the shapes of the blood vessel scaffolds during biodegradation. Adv. Mater. 29, 1700171 (2017).

130. Ito, A. et al. Novel methodology for fabrication of tissue-engineered tubular constructs using magnetite nanoparticles and magnetic force. Tissue Eng. 11 1553-1561 (2005).

131. Hsu A. R \& Ellington, J. K. Patient-specific 3-dimensional printed titanium truss cage with tibiotalocalcaneal arthrodesis for salvage of persisten distal tibia nonunion. Foot Ankle Spec. 8, 483-489 (2015).

132. Jeong, C. G. \& Atala, A. 3D printing and biofabrication for load bearing tissue engineering. Adv. Exp. Med. Biol. 881, 3-14 (2015)

133. Bose, S., Vahabzadeh, S. \& Bandyopadhyay, A. Bone tissue engineering using 3D printing. Mater. Today 16, 496-504 (2013)

134. McBeth, C. et al. 3D bioprinting of GelMA scaffolds triggers mineral deposition by primary human osteoblasts. Biofabrication 9, 015009 (2017)

135. Yao, Q. et al. Design, construction and mechanical testing of digital 3D anatomical data-based PCL-HA bone tissue engineering scaffold. J. Mater. Sci. Mater. Med. 26, 5360 (2015).

136. Wang, M. O., Piard, C. M., Melchiorri, A., Dreher, M. L. $\&$ Fisher, J. P. Evaluating changes in structure and cytotoxicity during in vitro degradation of threedimensional printed scaffolds. Tissue Eng. A 21 , 1642-1653 (2015).

137. Pati, F. et al. Ornamenting 3D printed scaffolds with cell-laid extracellular matrix for bone tissue regeneration. Biomaterials 37, 230-241 (2015).

138. Kang, H. W. et al. A 3D bioprinting system to produce human-scale tissue constructs with structural integrity. Nat. Biotechnol. 34, 312-319 (2016).

139. Ballyns, J. J. et al. Image-guided tissue engineering of anatomically shaped implants via MRI and micro-CT using injection molding. Tissue Eng. A 14, 1195-1202 (2008).

140. Hockaday, L. A. et al. Rapid 3D printing of anatomically accurate and mechanically heterogeneous aortic valve hydrogel scaffolds. Biofabrication 4, 035005 (2012)

141. Bowles, R. D., Gebhard, H. H., Hartl, R. \& Bonassar, L. J. Tissue-engineered intervertebral discs produce new matrix, maintain disc height, and restore biomechanical function to the rodent spine. Proc. Natl Acad. Sci. USA 108, 13106-13111 (2011).

142. Makris, E. A., Gomoll, A. H., Malizos, K. N., Hu, J. C. \& Athanasiou, K. A. Repair and tissue engineering techniques for articular cartilage. Nat. Rev. Rheumatol. 11, 21-34 (2015).

143. Tatman, P. D. et al. Multiscale biofabrication of articular cartilage: bioinspired and biomimetic approaches. Tissue Eng. B 21, 543-559 (2015).

144. Di Bella, C., Fosang, A., Donati, D. M., Wallace, G. G. $\alpha$ Choong, P. F. 3D bioprinting of cartilage for orthopedic surgeons: reading between the lines. Front. Surg. 2, 39 (2015).

145. Gruene, M. et al. Laser printing of stem cells for biofabrication of scaffold-free autologous grafts. Tissue Eng. C 17, 79-87 (2011).

146. Cui, X., Breitenkamp, K., Finn, M. G., Lotz, M. \& D'Lima, D. D. Direct human cartilage repair using three-dimensional bioprinting technology. Tissue Eng. A 18, 1304-1312 (2012)

147. Cui, X., Breitenkamp, K., Lotz, M. \& D'Lima, D. Synergistic action of fibroblast growth factor- 2 and transforming growth factor-beta1 enhances bioprinted human neocartilage formation. Biotechnol. Bioeng. 109, 2357-2368 (2012)

148. Xu, T. et al. Hybrid printing of mechanically and biologically improved constructs for cartilage tissue engineering applications. Biofabrication 5, 015001 (2013).

149. Mannoor, M. S. et al. 3D printed bionic ears. Nano Lett. 13, 2634-2639 (2013).

150. Almqvist, K. F. et al. Treatment of cartilage defects in the knee using alginate beads containing human mature allogenic chondrocytes. Am. J. Sport Med. 37 1920-1929 (2009).

151. Dhollander, A. A. M. et al. Midterm results of the treatment of cartilage defects in the knee using alginate beads containing human mature allogenic chondrocytes. Am. J. Sport Med. 40, 75-82 (2012).

152. Skardal, A. et al. Bioprinted amniotic fluid-derived stem cells accelerate healing of large skin wounds. Stem Cells Transl Med. 1, 792-802 (2012).

153. Yang, J. et al. Cell delivery in regenerative medicine: the cell sheet engineering approach. J. Control. Release 116, 193-203 (2006).

154. Iwata, T. et al. Cell sheet engineering and its application for periodontal regeneration. J. Tissue Eng. Regen. Med. 9, 343-356 (2015).

155. Frontera, W. R. \& Ochala, J. Skeletal muscle: a brief review of structure and function. Calcified Tissue Int 96, 183-195 (2015)

156. Ostrovidov, S. et al. Skeletal muscle tissue engineering: methods to form skeletal myotubes and their applications. Tissue Eng. Part B Rev. 20 403-436 (2014).

157. Gaebel, R. et al. Patterning human stem cells and endothelial cells with laser printing for cardiac regeneration. Biomaterials 32, 9218-9230 (2011).

158. Xu, T., Baicu, C., Aho, M., Zile, M. \& Boland, T Fabrication and characterization of bio-engineered cardiac pseudo tissues. Biofabrication 1, 035001 (2009).

159. Gaetani, R. et al. Cardiac tissue engineering using tissue printing technology and human cardiac progenitor cells. Biomaterials 33, 1782-1790 (2012).

160. Gao, L. et al. Myocardial tissue engineering with cells derived from human-induced pluripotent stem cells and a native-like, high-resolution, 3-dimensionally printed scaffold. Circ. Res. 120, 1318-1325 (2017).

161. Atala, A., Kasper, F. K. \& Mikos, A. G. Engineering complex tissues. Sci. Transl Med. 4, 160rv12 (2012)

162. Lee, C. H. et al. Regeneration of the articular surface of the rabbit synovial joint by cell homing: a proof of concept study. Lancet 376, 440-448 (2010).

163. Merceron, T. K. et al. A 3D bioprinted complex structure for engineering the muscle-tendon unit. Biofabrication 7, 035003 (2015).

164. Novosel, E. C., Kleinhans, C. \& Kluger, P. J. Vascularization is the key challenge in tissue engineering. Adv. Drug Deliv. Rev. 63, 300-311 (2011)

165. Jain, R. K., Au, P., Tam, J., Duda, D. G. \& Fukumura, D. Engineering vascularized tissue. Nat. Biotechnol. 23, 821-823 (2005)

166. Gross, B. C., Erkal, J. L., Lockwood, S. Y., Chen, C. \& Spence, D. M. Evaluation of 3D printing and its potential impact on biotechnology and the chemical sciences. Anal. Chem. 86, 3240-3253 (2014). 
167. Ozbolat, I. T. \& Yu, Y. Bioprinting toward organ fabrication: challenges and future trends. IEEE Trans. Biomed. Eng. 60, 691-699 (2013).

168. Zheng, Y. et al. Microstructured templates for directed growth and vascularization of soft tissue in vivo. Biomaterials 32, 5391-5401 (2011).

169. Choi, N. W. et al. Microfluidic scaffolds for tissue engineering. Nat. Mater. 6, 908-915 (2007)

170. Kolesky, D. B. et al. 3D bioprinting of vascularized heterogeneous cell-laden tissue constructs. Adv. Mater. 26, 3124-3130 (2014).

171. Attalla, R., Ling, C. \& Selvaganapathy, P. Fabrication and characterization of gels with integrated channels using 3D printing with microfluidic nozzle for tissue engineering applications. Biomed. Microdevices 18 17 (2016)

172. L'Heureux, N. et al. Human tissue-engineered blood vessels for adult arterial revascularization. Nat. Med. 12, 361-365 (2006)

173. Schubert, C., van Langeveld, M. C. \& Donoso, L. A. Innovations in 3D printing: a 3D overview from optics to organs. Br. J. Ophthalmol. 98, 159-161 (2014).

174. Kato-Negishi, M., Onoe, H., Ito, A. \& Takeuchi, S. Rodshaped neural units for aligned 3D neural network connection. Adv. Healthc. Mater. 6, 1700143 (2017).

175. de Vos, P., Faas, M. M., Strand, B. \& Calafiore, R. Alginate-based microcapsules for immunoisolation of pancreatic islets. Biomaterials 27, 5603-5617 (2006).

176. Vegas, A. J. et al. Combinatorial hydrogel library enables identification of materials that mitigate the foreign body response in primates. Nat. Biotechnol. 34, 345-352 (2016).

177. Rengifo, H. R., Giraldo, J. A., Labrada, I. \& Stabler, C. L. Long-term survival of allograft murine islets coated via covalently stabilized polymers. Adv. Healthc. Mater. 3 1061-1070 (2014).

178. Veiseh, O. et al. Size- and shape-dependent foreign body immune response to materials implanted in rodents and non-human primates. Nat. Mater. 14 643-651 (2015)

179. Vegas, A. J. et al. Long-term glycemic control using polymer-encapsulated human stem cell-derived beta cells in immune-competent mice. Nat. Med. 22 , 306-311 (2016)

180. Dufrane, D., Goebbels, R. M., Saliez, A., Guiot, Y. \& Gianello, P. Six-month survival of microencapsulated pig islets and alginate biocompatibility in primates: proof of concept. Transplantation 81, 1345-1353 (2006).

181. Elliott, R. B. et al. Live encapsulated porcine islets from a type 1 diabetic patient $9.5 \mathrm{yr}$ after xenotransplantation. Xenotransplantation 14, 157-161 (2007)

182. Capone, S. H. et al. Impact of alginate composition: from bead mechanical properties to encapsulated HepG2/C3A cell activities for in vivo implantation. PLOS ONE 8, e62032 (2013).

183. Song, W. et al. Engraftment of human induced pluripotent stem cell-derived hepatocytes in immunocompetent mice via 3D co-aggregation and encapsulation. Sci. Rep. 5, 16884 (2015)

184. Qi, M. et al. PVA hydrogel sheet macroencapsulation for the bioartificial pancreas. Biomaterials 25 . 5885-5892 (2004).

185. Veriter, S. et al. The impact of hyperglycemia and the presence of encapsulated islets on oxygenation within a bioartificial pancreas in the presence of mesenchyma stem cells in a diabetic Wistar rat model. Biomaterials 32, 5945-5956 (2011).

186. Fozdar, D. Y., Soman, P., Lee, J. W., Han, L. H. \& Chen, S. Three-dimensional polymer constructs exhibiting a tunable negative poisson's ratio. Adv. Funct. Mater. 21, 2712-2720 (2011).

187. Lee, H. \& Cho, D. W. One-step fabrication of an organ-on-a-chip with spatial heterogeneity using a 3D bioprinting technology. Lab. Chip 16, 2618-2625 (2016).

188. Clausen, A. Wang F, Jensen, J. S., Sigmund, O. \& Lewis, J. A. Topology optimized architectures with programmable Poisson's ratio over large deformations. Adv. Mater. 27, 5523-5527 (2015).

189. Shan, S. et al. Multistable architected materials for trapping elastic strain energy. Adv. Mater. 27, 4296-4301 (2015)

190. Martin, J. J., Fiore, B. E. \& Erb, R. M. Designing bioinspired composite reinforcement architectures via 3D magnetic printing. Nat. Commun. 6, 8641 (2015).

191. Han, X., Bibb, R. \& Harris, R. Engineering design of artificial vascular junctions for 3D printing. Biofabrication 8, 025018 (2016)

192. Sun, Y., Yang, X. \& Wang, Q. In-silico analysis on biofabricating vascular networks using kinetic Monte Carlo simulations. Biofabrication 6, 015008 (2014).
193. Yang, X., Mironov, V. \& Wang, Q. Modeling fusion of cellular aggregates in biofabrication using phase field theories. J. Theor. Biol. 303, 110-118 (2012).

194. McCune, M., Shafiee, A., Forgacs, G. \& Kosztin, I. Predictive modeling of post bioprinting structure formation. Soft Matter 10, 1790-1800 (2014).

195. Zhu, W. et al. 3D printing of functional biomaterials for tissue engineering. Curr. Opin. Biotechnol. 40 103-112 (2016)

196. Tumbleston, J. R. et al. Additive manufacturing. Continuous liquid interface production of 3D objects. Science 347, 1349-1352 (2015).

197. Janusziewicz, R., Tumbleston, J. R., Quintanilla, A. L., Mecham, S. J. \& DeSimone, J. M. Layerless fabrication with continuous liquid interface production. Proc. Natl Acad. Sci. USA 113, 11703-11708 (2016).

198. Shanjani, Y., Pan, C. C., Elomaa, L. \& Yang, Y. A novel bioprinting method and system for forming hybrid tissue engineering constructs. Biofabrication 7 045008 (2015).

199. Hoffmann, A et al New stereolithographic resin providing functional surfaces for biocompatible three-dimensional printing. J. Tissue Eng. 8, 2041731417744485 (2017).

200. Morris, V. B., Nimbalkar, S., Younesi, M., McClellan, P. \& Akkus, O. Mechanical properties, cytocompatibility and manufacturability of chitosan:PEGDA hybrid-gel scaffolds by stereolithography. Ann. Biomed. Eng. 45 286-296 (2017)

201. Serpooshan, V. et al. Bioacoustic-enabled patterning of human iPSC-derived cardiomyocytes into 3D cardiac tissue. Biomaterials 131, 47-57 (2017).

202. Bouyer, C. et al. A bio-acoustic levitational (BAL) assembly method for engineering of multilayered, 3D brain-like constructs, using human embryonic stem cell derived neuro-progenitors. Adv. Mater. 28, 161-167 (2016).

203. Durmus, N. G. et al. Magnetic levitation of single cells. Proc. Natl Acad. Sci. USA 112, E3661-E3668 (2015)

204. Li, Y. et al. Rapid assembly of heterogeneous 3D cell microenvironments in a microgel array. Adv. Mater. 28, 3543-3548 (2016).

205. O'Bryan, C. S. et al. Self-assembled micro-organogels for 3D printing silicone structures. Sci. Adv. 3, e1602800 (2017)

206. Vrij, E. et al. Directed Assembly and Development of Material-Free Tissues with Complex Architectures. Adv. Mater. 28, 4032-4039 (2016).

207. Fernandez, J. G. \& Khademhosseini, A. Micro-masonry: construction of 3D structures by microscal self-assembly. Adv. Mater. 22, 2538-2541 (2010).

208. Oi, H. et al. DNA-directed self-assembly of shapecontrolled hydrogels. Nature Commun. 4, 2275 (2013).

209. Todhunter, M. E. et al. Programmed synthesis of three dimensional tissues. Nat. Methods 12, 975-981 (2015).

210. Tasoglu, S., Diller, E., Guven, S., Sitti, M. \& Demirci, U. Untethered micro-robotic coding of three-dimensional material composition. Nat. Commun. 5, 3124 (2014).

211. Dondossola, E. et al. Examination of the foreign body response to biomaterials by nonlinear intravita microscopy. Nat. Biomed. Eng. 1, 0007 (2016).

212. Doloff, J. C. et al. Colony stimulating factor-1 receptor is a central component of the foreign body response to biomaterial implants in rodents and non-human primates. Nat. Mater. 16, 671-680 (2017).

213. Gullo, M. R., Takeuchi, S. \& Paul, O. Multicellular biohybrid materials: probing the interplay of cells of different types precisely positioned and constrained on 3D wireframe-like microstructures. Adv. Healthc. Mater. 6, 1601053 (2017).

214. Nava, M. M., Zandrini, T., Cerullo, G., Osellame, R. \& Raimondi, M. T. 3D stem cell niche engineering via two-photon laser polymerization. Methods Mol. Biol. 1612, 253-266 (2017).

215. Richter, B et al Guiding cell attachment in 3D microscaffolds selectively functionalized with two distinct adhesion proteins. Adv. Mater. 29, 1604342 (2017).

216. Villar, G., Graham, A. D. \& Bayley, H. A tissue-like printed material. Science 340, 48-52 (2013).

217. Chiang, M. Y., Hsu, Y. W., Hsieh, H. Y., Chen, S. Y. \& Fan, S. K. Constructing 3D heterogeneous hydrogels from electrically manipulated prepolymer droplets and crosslinked microgels. Sci. Adv. 2, e1600964 (2016).

218. Inostroza-Brito, K. E. et al. Cross-linking of a biopolymer-peptide co-assembling system. Acta Biomaterialia 50, 80-89 (2017)

219. Hardin, J. O., Ober, T. J., Valentine, A. D. \& Lewis, J. A. Microfluidic printheads for multimaterial 3D printing of viscoelastic inks. Adv. Mater. 27, 3279-3284 (2015).
220. Snyder, J., Son, A. R., Hamid, Q., Wu, H. \& Sun, W. Hetero-cellular prototyping by synchronized multimaterial bioprinting for rotary cell culture system. Biofabrication 8, 015002 (2016)

221. Duchi, S. et al. Handheld co-axial bioprinting: application to in situ surgical cartilage repair. Sci. Rep. 7, 5837 (2017)

222. Mogas-Soldevila, L., Duro-Royo, J. \& Oxman, N. Water-based robotic fabrication: large-scale additive manufacturing of functionally graded hydrogel composites via multichamber extrusion. 3D Print. Addit. Manuf. 1, 141-151 (2014).

223. Schuurman, W. et al. Bioprinting of hybrid tissue constructs with tailorable mechanical properties. Biofabrication 3, 021001 (2011).

224. Graham, A. D. et al. High-resolution patterned cellular constructs by droplet-based 3D printing. Sci. Rep. 7 , 7004 (2017).

225. Gu, Q., Tomaskovic-Crook, E., Wallace, G. G. \& Crook, J. M. 3D bioprinting human induced pluripotent stem cell constructs for in situ cell proliferation and successive multilineage differentiation. Adv. Healthc Mater. 6, 1700175 (2017).

226. Zujur, D. et al. Three-dimensional system enabling the maintenance and directed differentiation of pluripotent stem cells under defined conditions. Sci. Adv. 3 e1602875 (2017)

227. Whulanza, Y., Ucciferri, N., Domenici, C., Vozzi, G. $\delta$ Ahluwalia, A. Sensing scaffolds to monitor cellular activity using impedance measurements. Biosens. Bioelectron. 26, 3303-3308 (2011)

228. Orsi, G et al. Combining inkjet printing and sol-gel chemistry for making $\mathrm{pH}$-sensitive surfaces. Curr. Top. Med. Chem. 15, 271-278 (2015).

229. Muskovich, M. \& Bettinger, C. J. Biomaterials-based electronics: polymers and interfaces for biology and medicine. Adv. Healthc. Mater. 1, 248-266 (2012).

230. Minev, I. R et al. Biomaterials. Electronic dura mater for long-term multimodal neural interfaces. Science 347, 159-163 (2015)

231. Tatara, A. M. et al. Reconstruction of large mandibular defects using autologous tissues generated from in vivo bioreactors. Acta Biomater. 45, 72-84 (2016)

232. Emans, P. J. et al. Autologous engineering of cartilage. Proc. Natl Acad. Sci. USA 107, 3418-3423 (2010).

233. Kluin, J. et al. In situ heart valve tissue engineering using a bioresorbable elastomeric implant - from material design to 12 months follow-up in sheep. Biomaterials 125, 101-117 (2017).

234. Rothuizen, T. C. et al. Development and evaluation of in vivo tissue engineered blood vessels in a porcine model. Biomaterials 75, 82-90 (2016).

235. Di Bella, C. et al. In-situ handheld 3D Bioprinting for cartilage regeneration. J. Tissue Eng. Regen. Med. 12, 611-621 (2017).

236. Gladman, A. S., Matsumoto, E. A., Nuzzo, R. G. Mahadevan, L. \& Lewis, J. A. Biomimetic 4D printing. Nat. Mater. 15, 413-418 (2016).

237. Hendrikson, W. J. et al. Towards 4D printed scaffolds for tissue engineering: exploiting 3D shape memory polymers to deliver time-controlled stimulus on cultured cells. Biofabrication 9, 031001 (2017).

238. Peltola, S. M. et al. A review of rapid prototyping techniques for tissue engineering purposes. Ann. Med. 40, 268-280 (2008)

239. Malda, J. et al. 25th anniversary article: Engineering hydrogels for biofabrication. Adv. Mater. 25 5011-5028 (2013).

\section{Acknowledgements}

L.M. acknowledges the Dutch Province of Limburg and the European Research Council (grant \#637308) for funding. J.A.B. thanks the AO foundation for funding. S.J.L. and J.J.Y. were supported by the US National Institutes of Health (1P41EB023833-01). S.T. and Y.M. thank A. Shima, S. Nagata and F. Ozawa for valuable discussion.

Author contributions

All authors contributed equally to the preparation of this manuscript.

Competing interests

The authors declare no competing interests.

\section{Publisher's note}

Springer Nature remains neutral with regard to jurisdictional claims in published maps and institutional affiliations.

RELATED LINKS

Taylor \& Francis Ltd: http://www.tandfonline.com 